\title{
Test and Analysis of Buckling-Critical Stiffened Metallic Launch Vehicle Cylinders
}

\author{
Mark W. Hilburger*, and Michael C. Lindell ${ }^{\dagger}$ \\ NASA Langley Research Center, Hampton, Virginia, 23681, USA \\ W. Allen Waters \\ Analytical Mechanics Associates, Hampton, Virginia, 23681, USA \\ Nathaniel W. Gardner $\$$ \\ Analytical Services and Materials, Hampton, Virginia, 23681, USA
}

\begin{abstract}
A summary of a NASA design analysis and test program on the buckling of large-scale, integrally-stiffened metallic cylinders is presented. The test article designs were developed based on proposed NASA launch vehicle cylinder designs and span a significant portion of the design space. Various loading conditions were applied to the cylinders and include different combinations of axial compression, bending, and internal pressure loads that simulate typical launch vehicle loading scenarios. The data gathered from this test program is being used to develop and validate new analysis-based knockdown factors and design guidelines for these stiffened metallic cylinders. In this paper, the test article designs and fabrication methods are described along with the test facilities and instrumentation. Selected test and finite element analysis results are presented and compared and are used to illustrate the typical response characteristics of the stiffened metallic cylinders considered. Overall, good qualitative agreement is found, however, several discrepancies in the results were identified across several of the tests. The discrepancies were investigated thoroughly and can be attributed to variations in the as-built skin and stiffener geometry, variations in the measured geometric imperfection, and modeling assumptions associated with the boundary conditions, and loading imperfections. Based on these findings, several refinements were made to the finite element models which significantly improved the correlation between the test and analysis results. These modeling refinements are described and the updated analysis results are presented.
\end{abstract}

\section{Nomenclature}

2D $\quad=$ Two-dimensional

3D $=$ Three-dimensional

$a \quad=$ isogrid stiffener length

$A_{11}, A_{22}=$ membrane stiffnesses in the axial and the circumferential directions, respectively

$b \quad=$ isogrid stiffener thickness

$b_{r} \quad=$ orthogrid ring spacing

$b_{s} \quad=$ orthogrid stiffener spacing

$\mathrm{CS}=$ Core Stage

$D_{11}, D_{22}=$ bending stiffnesses in the axial and the circumferential directions, respectively

DIC $=$ Digital image correlation

$\mathrm{E}_{\mathrm{c}} \quad=$ Compression modulus

$\mathrm{E}_{\mathrm{t}} \quad=$ Tension modulus

\footnotetext{
${ }^{*}$ Senior Research Engineer, Structural Mechanics and Concepts Branch, Senior Member AIAA.

$\dagger$ Senior Structural Analyst, Structural and Thermal Systems Branch, Senior Member AIAA.

* Staff Structural Engineer, Structural Mechanics and Concepts Branch, Senior Member AIAA.

$\S$ Research Engineer, Structural Mechanics and Concepts Branch, Senior Member AIAA.
} 


$\begin{array}{ll}H & =\text { stiffener height measured from OLM } \\ \text { IML } & =\text { inner mold line } \\ \text { imp } & =\text { imperfection variable } \\ \text { LaRC } & =\text { NASA Langley Research Center } \\ \text { LVDT } & =\text { Linear voltage displacement transducer } \\ \text { MSFC } & =\text { NASA Marshall Space Flight Center } \\ \text { NESC } & =\text { NASA Engineering and Safety Center } \\ \text { OML } & =\text { Outer mold line } \\ \text { SBKF } & =\text { Shell Buckling Knockdown Factor Project } \\ \text { SLS } & =\text { Space Launch System } \\ t & =\text { skin thickness } \\ t_{e f f} & =\text { effective shell wall thickness, } t_{\text {eff }}=\sqrt[4]{\frac{144 D_{11} D_{22}}{A_{11} A_{22}}} \\ t_{r} & =\text { orthogrid ring thickness } \\ t_{s} & =\text { orthogrid stringer thickness } \\ t_{t} & =\text { weld land transition skin thickness } \\ t_{w} & =\text { weld land thickness } \\ \text { US } & =\text { Upper Stage } \\ u, v, w & =\text { axial, circumferential, and radial displacements } \\ w_{t} & =\text { weld land transition width } \\ w_{w} & =\text { weld land half width } \\ x, \theta, z & =\text { axial, circumferential, and radial coordinates }\end{array}$

\section{Introduction}

$\mathrm{H}$ gh-performance launch vehicle shell structures are inherently thin walled because of weight and performance considerations and are often subjected to destabilizing loads during flight. Thus, buckling is an important and often critical consideration in the design of these structures and reliable, validated design criteria for thin-walled shells are needed. Unfortunately, the current buckling design guidelines (Refs. 1-4) have not been updated since they were first published by NASA in the late 1960s and do not take full advantage of modern materials, precision manufacturing processes, and new structural concepts being considered in for the next generation of launch vehicles.

In 2007, the NASA Engineering and Safety Center (NESC) established the Shell Buckling Knockdown Factor (SBKF) project with the goal of developing updated buckling design factors (a.k.a. knockdown factors) for selected metallic and composite launch-vehicle cylindrical shell structures. A significant part of this effort includes the design and execution of buckling tests on launch-vehicle-like cylindrical shells. The data obtained from these tests are subsequently being used to develop and validate high-fidelity buckling simulations and new analysis-based knockdown factors.

SBKF has recently completed a comprehensive test program to investigate the buckling response of integrallystiffened metallic cylinders that included the testing of eight subscale 8-ft-diameter cylinders and two full-scale 27.5$\mathrm{ft}$-diameter cylinders. The test article designs were developed based on proposed NASA launch vehicle cylinder designs and span a significant portion of the design space. Various loading conditions were applied to the cylinders and include different combinations of axial compression, bending, and internal pressure loads that simulate typical launch vehicle loading scenarios. The data gathered from this test program is currently being used to develop and validate new analysis-based knockdown factors and design guidelines for these stiffened metallic cylinders.

The objective of this paper is to provide a summary of the SBKF test program on the 8-ft-diameter integrallystiffened metallic cylinders and highlight selected test and analysis results from a representative cylinder test article. First, the test article designs and fabrication methods are described along with the test facilities and instrumentation. Then, the finite element models and analysis methods are discussed. Finally, selected test and analysis results are presented and compared. These results will be used to illustrate the typical response characteristics of the stiffened metallic cylinders considered and the specific modeling details and refinements necessary to provide accurate shell buckling predictions and design data. 


\section{Test Description}

\section{A. Test Article Configuration}

The subscale cylindrical test articles have an 8-ft-diameter and are 6.5-ft-long (nominal dimensions). Each test article was constructed from three integrally-stiffened, 2195 Al-Li curved-panel segments $\left(120^{\circ}\right.$ arc segments) that were friction-stir welded together to form a complete cylinder. The stiffener configurations were chosen based on NASA launch vehicle cylinder designs from the Ares 1 Upper Stage (US), Ares 5 Core Stage (CS) and the Space Launch System (SLS) CS and included internal orthogrid and isogrid stiffener patterns. The orthogrid stiffener pattern and design variables are shown in Fig. 1 , where $t$ is the skin thickness, $t_{s}$ is the stringer thickness, $t_{r}$ is the ring thickness, $H$ is the total stiffener height, $b_{s}$ is the stringer spacing, and $b_{r}$ is the ring spacing. The isogrid stiffener pattern and design variables are shown in Fig. 2, where $t$ is the skin thickness, $H$ is the total stiffener height, $b$ is the stiffener thickness, and $a$ is the stiffener length.

The test articles included similar design features as those found in state-of-the-art launch-vehicle cylinder structures to maximize the relevance of the test data to the design of future launch vehicles. These design features include radius fillets at the intersection between the skin and stiffeners and at the intersection between stiffeners (see radius features in Figs. 1 and 2), and representative weld land designs. Subscale axial and circumferential weld land designs were developed based on a typical Space Shuttle External Tank (ET) design (see Fig. 3a) and a proposed SLS CS design (see Fig. 3b). The ET-based design includes a transition region in which the axial and circumferential stiffeners gradually taper down into the monocoque weld land region and the skin thickness is increased. This type of design is referred to as a tapered stiffener (TS) design. The SLS-type weld land and transition regions have many of the same features as the ET design, however, the circumferential stiffeners in the SLS design do not gradually taper down into the monocoque weld land region, rather the stiffeners terminate at an axial stiffener adjacent to the weld land. This type of design is referred to as a picture frame $(\mathrm{PF})$ design.

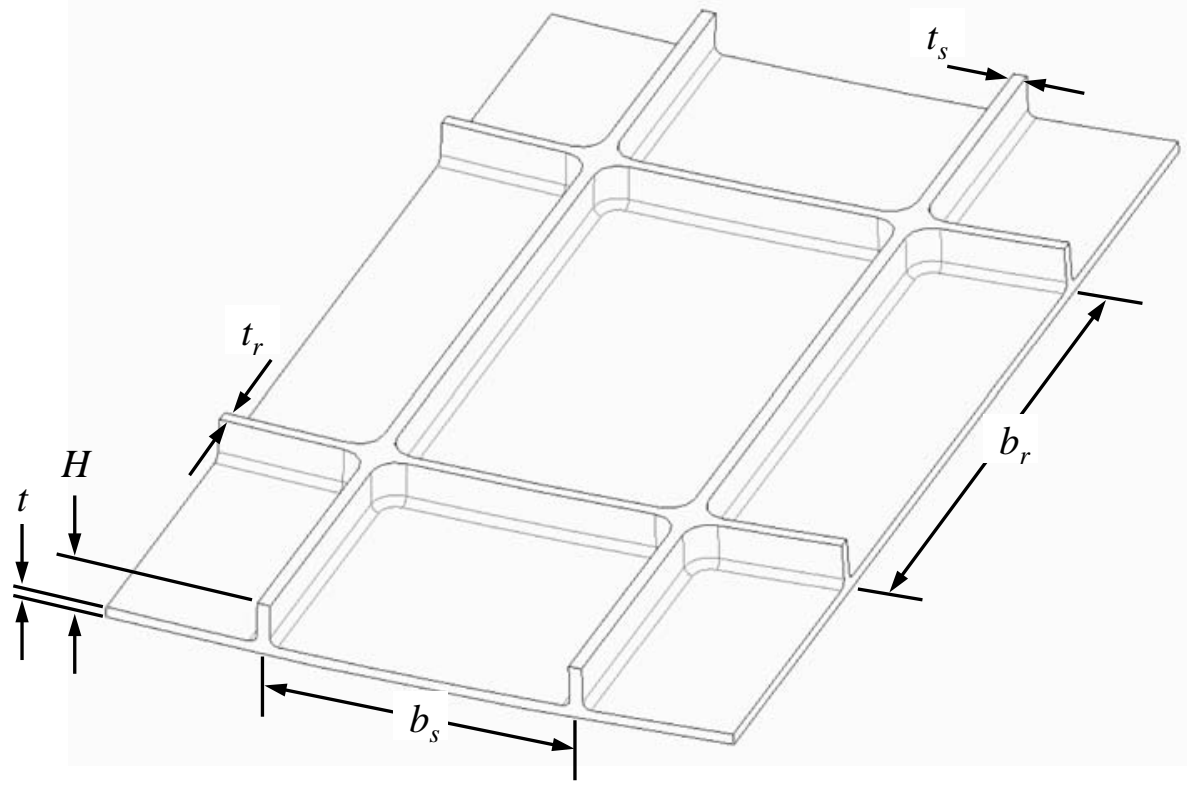

Figure 1. Orthogrid geometry definition. 


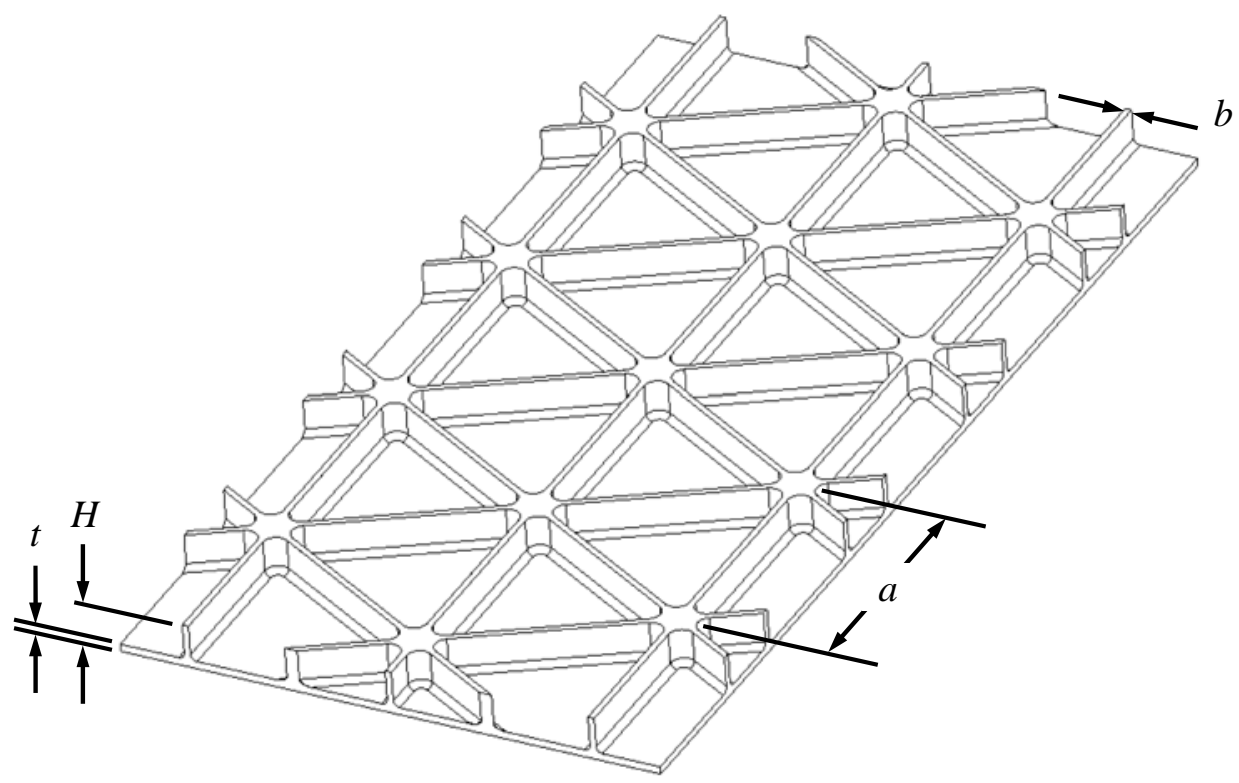

Figure 2. Isogrid geometry definition.

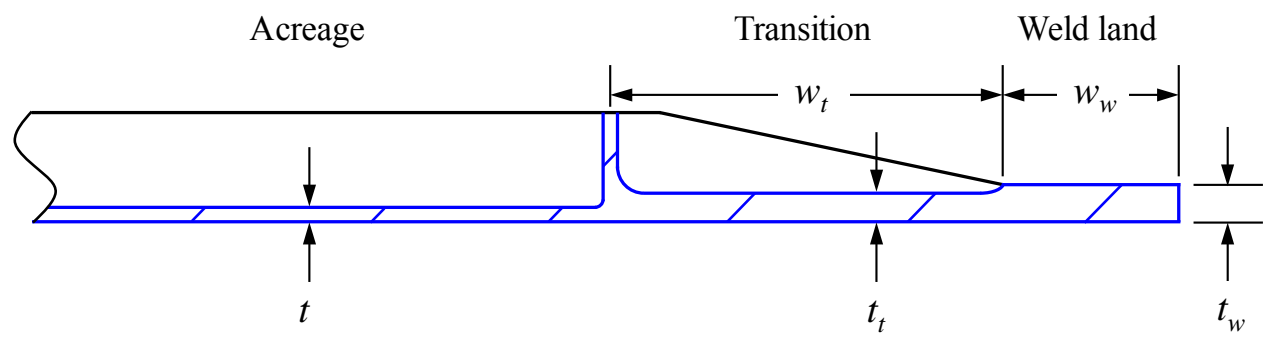

a) Typical acreage and weld land design with a tapered stiffener transition.

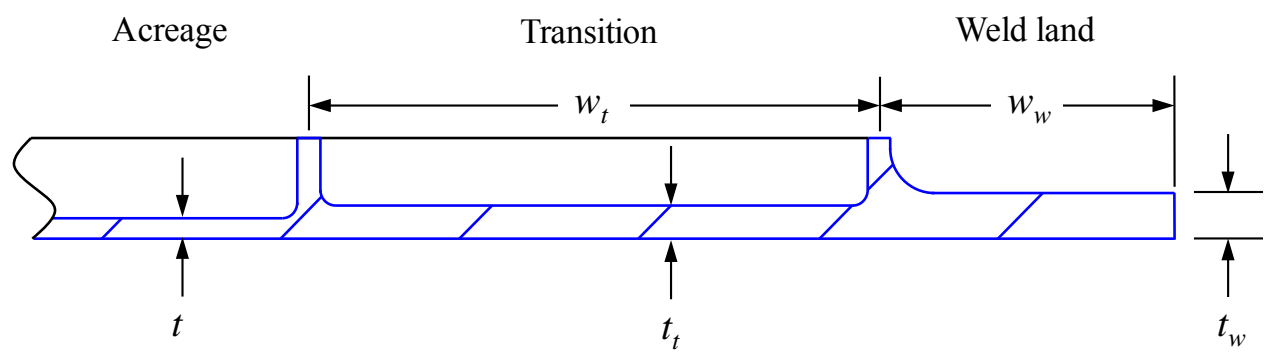

b) Typical acreage and weld land design with a "picture frame" stiffener transition.

Figure 3. Weld land geometry definition (shown in shown in the flat condition used for machining). 
The orthogrid and isogrid test article designs are summarized in Tables 1 and 2, respectively, and include the acreage design variables, weld land type and dimensions, and the corresponding cylinder-radius-to-effective-thickness ratio $R / t_{\text {eff. }} R$ is the outer mold line (OML) radius of the cylinder and the effective shell wall thicknesses of the stiffened acreage $t_{\text {eff }}$ is defined as:

$$
t_{\text {eff }}=\sqrt[4]{\frac{144 D_{11} D_{22}}{A_{11} A_{22}}}
$$

where $D_{11}$ and $D_{22}$ are the bending stiffnesses in the axial and circumferential directions, respectively, and $A_{11}$ and $A_{22}$ are the membrane stiffnesses in the axial and the circumferential directions, respectively. ${ }^{5} R / t_{\text {eff }}$ values range from 80.1 to 230.9 and cover a significant portion of the relevant launch vehicle design space.

Table 1. Orthogrid-stiffened test article designs

\begin{tabular}{|c|c|c|c|c|c|c|c|c|c|c|c|l|}
\hline $\begin{array}{c}\text { Test } \\
\text { Article }\end{array}$ & $\begin{array}{c}\text { Weld } \\
\text { Land }\end{array}$ & $\boldsymbol{t}$ & $\boldsymbol{H}$ & $\boldsymbol{t}_{\boldsymbol{s}}$ & $\boldsymbol{t}_{\boldsymbol{r}}$ & $\boldsymbol{b}_{\boldsymbol{s}}$ & $\boldsymbol{b}_{\boldsymbol{r}}$ & $\boldsymbol{w}_{\boldsymbol{w}}$ & $\boldsymbol{t}_{\boldsymbol{w}}$ & $\begin{array}{c}\boldsymbol{w}_{\boldsymbol{t}} \\
\text { (axial/circ.) }\end{array}$ & $\boldsymbol{t}_{\boldsymbol{t}}$ & $\boldsymbol{R}^{/ \boldsymbol{t}_{\text {eff }}}$ \\
\hline $\mathrm{TA} 01$ & $\mathrm{TS}$ & 0.100 & 0.400 & 0.100 & 0.100 & 4.000 & 4.000 & 1.258 & 0.250 & $1.688 / 1.016$ & 0.160 & 230.9 \\
\hline TA02 & TS & 0.100 & 0.400 & 0.100 & 0.100 & 4.000 & 4.000 & 1.258 & 0.250 & $1.688 / 1.016$ & 0.160 & 230.9 \\
\hline TA03 & TS & 0.060 & 0.723 & 0.065 & 0.600 & 1.813 & 4.314 & 1.258 & 0.200 & $1.333 / 0.971$ & 0.100 & 80.1 \\
\hline TA04 & TS & 0.060 & 0.723 & 0.065 & 0.600 & 1.813 & 4.314 & 1.258 & 0.200 & $1.333 / 0.971$ & 0.100 & 80.1 \\
\hline TA07 & PF & 0.090 & 0.440 & 0.105 & 0.100 & 2.364 & 4.400 & 1.256 & 0.200 & $0.666 / 2.364$ & 0.145 & 172.9 \\
\hline TA09 & PF & 0.070 & 0.570 & 0.065 & 0.065 & 2.009 & 4.900 & 1.267 & 0.200 & $0.774 / 2.009$ & 0.135 & 125.7 \\
\hline
\end{tabular}

Table 2. Isogrid-stiffened test article designs

\begin{tabular}{|c|c|c|c|c|c|c|c|c|c|c|}
\hline $\begin{array}{c}\text { Test } \\
\text { Article }\end{array}$ & $\begin{array}{c}\text { Weld } \\
\text { Land }\end{array}$ & $\boldsymbol{t}$ & $\boldsymbol{H}$ & $\boldsymbol{b}$ & $\boldsymbol{a}$ & $\boldsymbol{w}_{\boldsymbol{w}}$ & $\boldsymbol{t}_{\boldsymbol{w}}$ & $\begin{array}{c}\boldsymbol{w}_{\boldsymbol{t}} \\
\text { (axial/circ.) }\end{array}$ & $\boldsymbol{t}_{\boldsymbol{t}}$ & $\boldsymbol{R} / \boldsymbol{t}_{\text {eff }}$ \\
\hline \hline ITA01 & PF & 0.065 & 0.495 & 0.065 & 2.449 & 1.260 & 0.200 & $0.611 / 2.120$ & 0.135 & 101.4 \\
\hline ITA02 & PF & 0.080 & 0.460 & 0.065 & 2.130 & 1.251 & 0.200 & $0.551 / 1.844$ & 0.140 & 111.4 \\
\hline
\end{tabular}

\section{B. Test Article Fabrication}

Three curved panel segments were used to construct each cylinder and were fabricated in a three-step process. First, flat integrally-stiffened panels were fabricated by machining the stiffener pattern into 2195-T3 Al-Li flat-plate material to form the pockets and weld land details (see Fig. 4). After machining, the panels were visually inspected for flaws and the skin pocket thicknesses, and stiffener heights and thicknesses were measured to verify that they were built to specified tolerances. Following inspection, the flat orthogrid panels were bump-formed (while in the -T3 temper) into curved panel segments with an OML radius of 48 inches using a brake press (see Fig. 5). Finally, the panels were heat treated and aged to a-T83 temper. Once the panels were fabricated, they were friction-stir welded together along the axial weld lands to form a cylinder with an 8-foot (96-inch) OML diameter and 6.5-foot (78-inch) length (see Fig. 6). Each weld was subjected to a series of visual and ultrasonic quality inspections. No defects or anomalies were identified in the welds. 


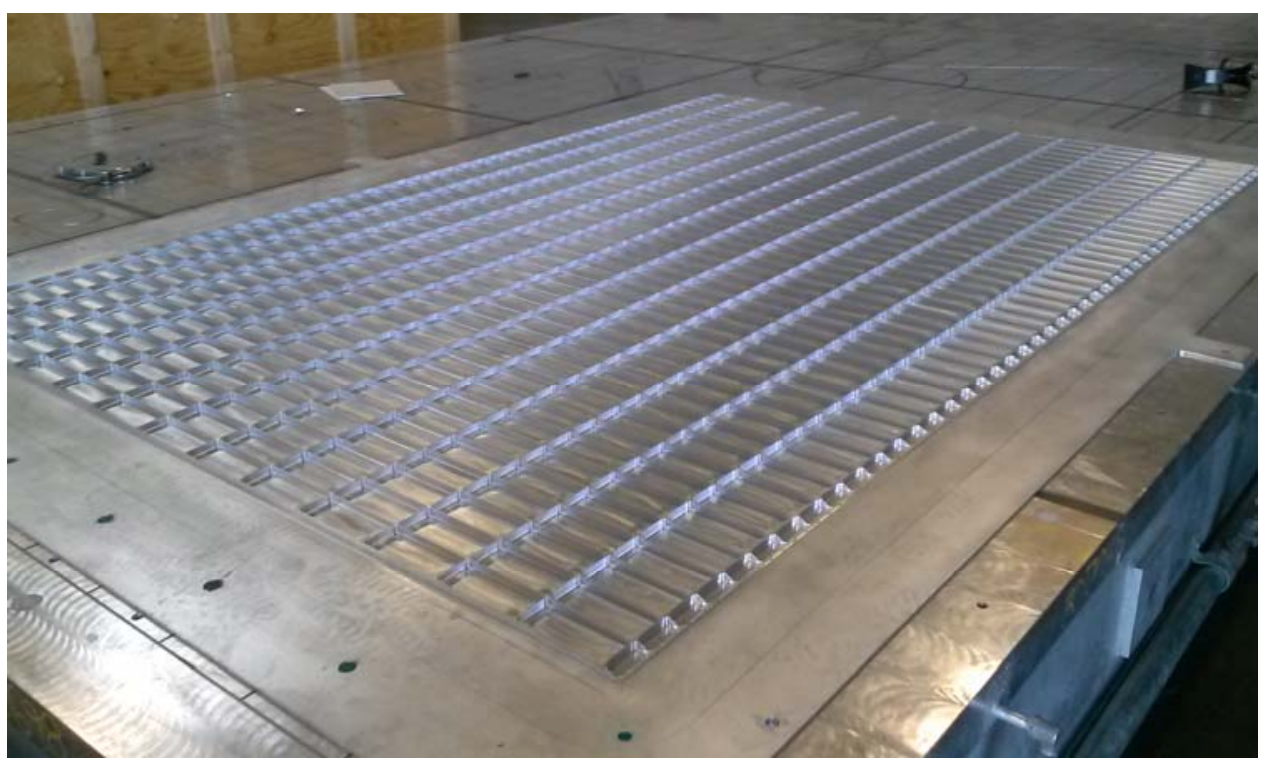

Figure 4. Typical orthogrid-stiffened panel.

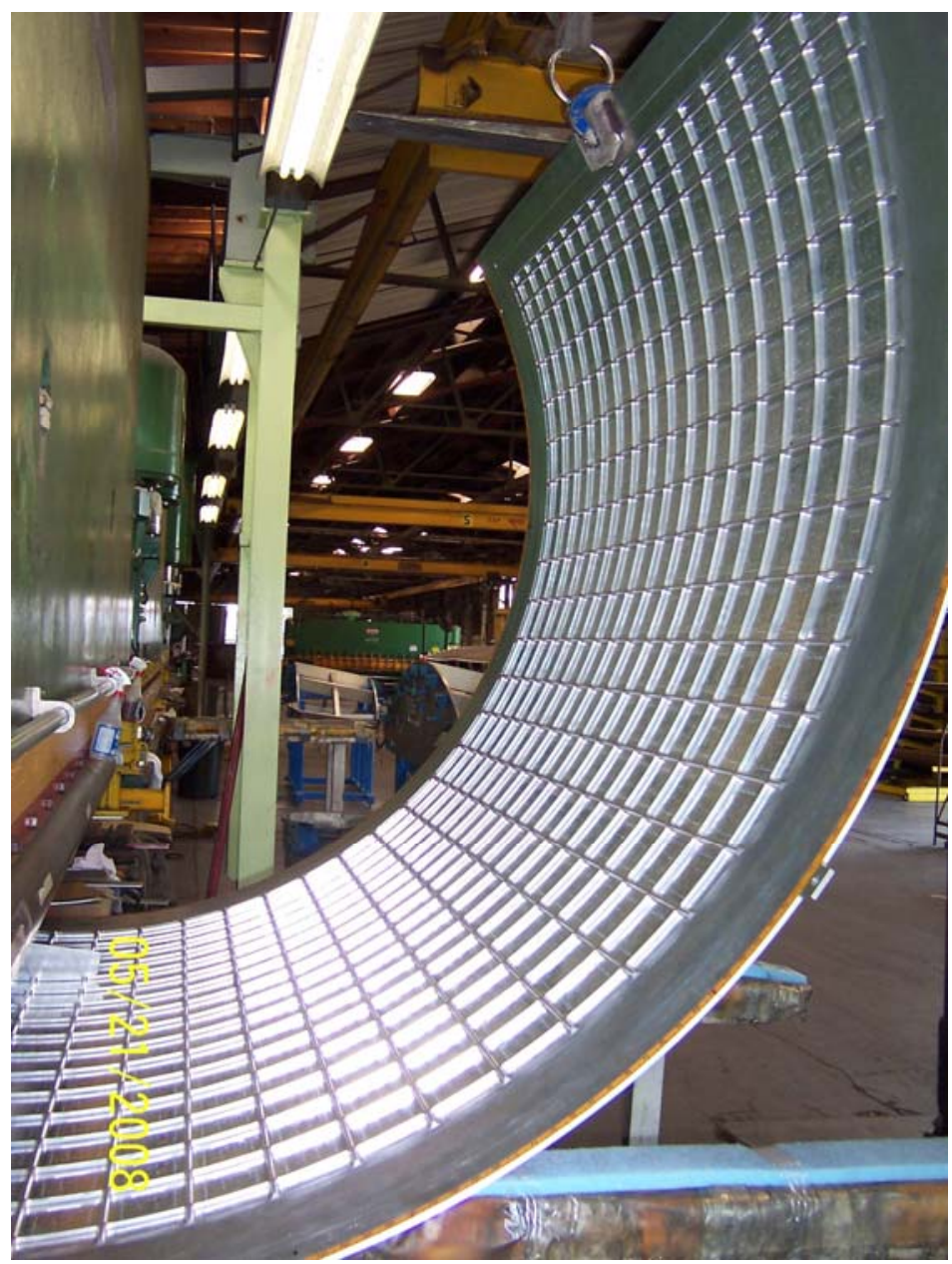

Figure 5. Typical orthogrid-stiffened panel during the bump-forming process.

American Institute of Aeronautics and Astronautics 


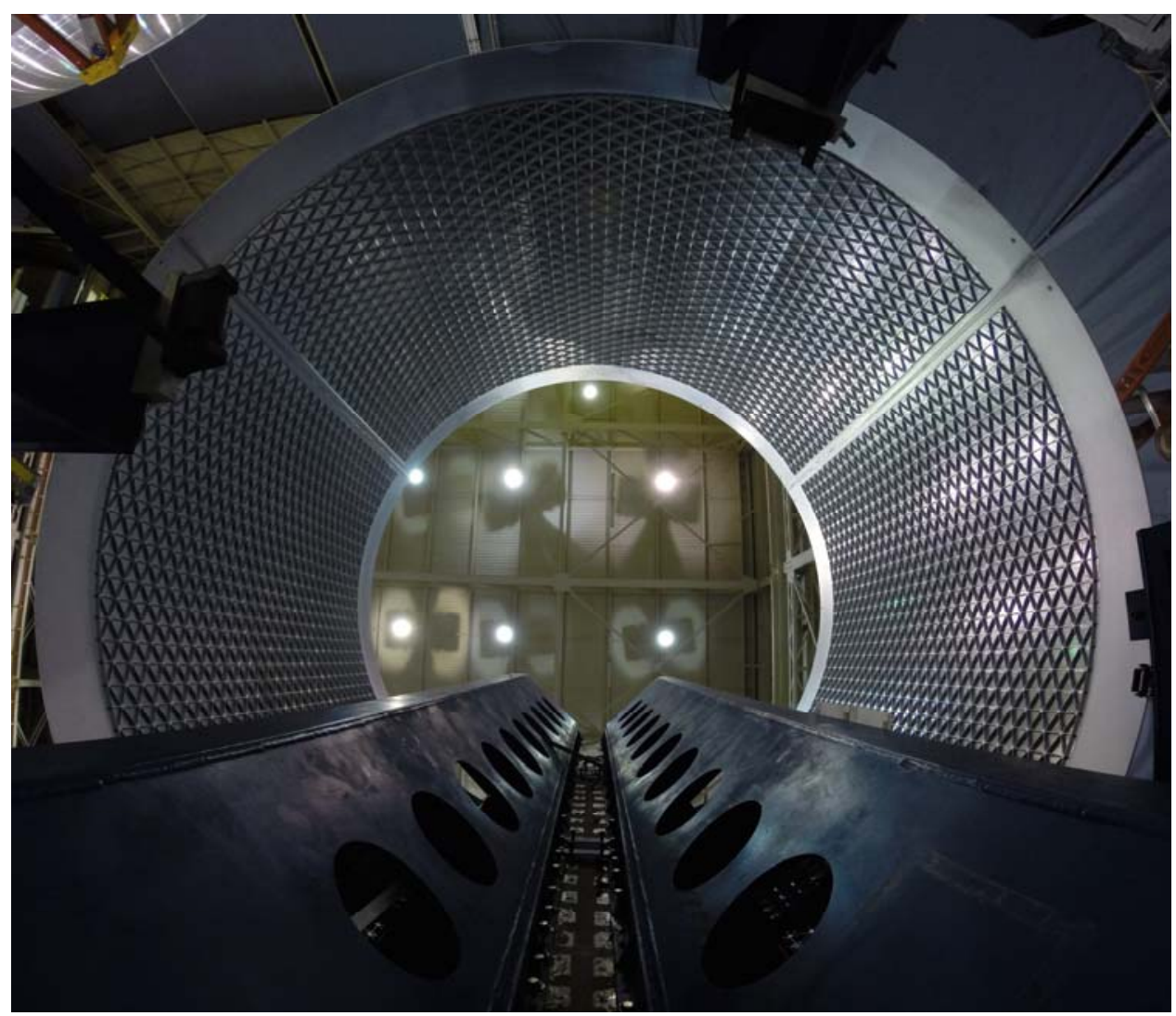

Figure 6. Inside view of an isogrid-stiffned test article installed in the vertical weld tool (view looking up from bottom of cylinder).

After the panels had been welded together into a cylinder, the ends of the test articles were machined flat and parallel to specified manufacturing tolerances in an effort to provide uniform load introduction into the test article. The top and bottom ends of the test articles were measured to verify the flatness and parallelism. On average, the top and bottom ends of the test articles were flat to within 0.010 inches, and parallel to each other to within 0.023 inches. Once machining and inspection were complete, each end of the test article was potted in a single-piece steel attachment ring using a low-melting-point alloy. An internal view of a typical orthogrid-stiffened test article with attachment rings installed is shown in Fig. 7 and the cross-section of the test article and attachment ring interface is shown in Fig. 8. Through-bolts were spaced every $20^{\circ}$ around the circumference of each attachment ring, and used as a fail-safe precaution in case the potting material failed during handling or testing. Concentricity and bolt-hole alignment specifications for the top and bottom attachment rings were maintained to minimize any loads that would result from the misalignment of the test assembly. Shims were used to position the test article in the attachment rings and adjust concentricity prior to potting. Once potted, the as-built geometry of the outer cylinder surface was measured using a structured-light measurement technique. A typical measured geometric imperfection from TA07 is shown in Fig. 9 and corresponds to the difference between the measured OML geometry and an ideal circular cylinder. The coordinate system used to display this imperfection data is defined in Fig. 10. Per this coordinate system, the location of panel A is between $-60^{\circ}$ and $+60^{\circ}$, panel $\mathrm{B}$ is between $+60^{\circ}$ and $180^{\circ}$, and panel $\mathrm{C}$ is between $180^{\circ}$ and $-60^{\circ}$. The weld lands were named after the panels they join: $\mathrm{A} / \mathrm{B}, \mathrm{B} / \mathrm{C}$ and $\mathrm{C} / \mathrm{A}$. The blue and red colored contours in Fig. 9 correspond to inward and outward radial imperfections, respectively. The measured imperfection exhibits distinct inward imperfections at the three axial weld lands, at $\theta=-60^{\circ}, 60^{\circ}$, and $180^{\circ}$, of approximately -0.10 inches and smaller magnitude variations in the acreage of the cylinder. This measured imperfection shape and amplitude were typical for the 8-ft-diameter cylinders tested and share many common features as those seen in full-scale welded cylinders. ${ }^{6}$ 


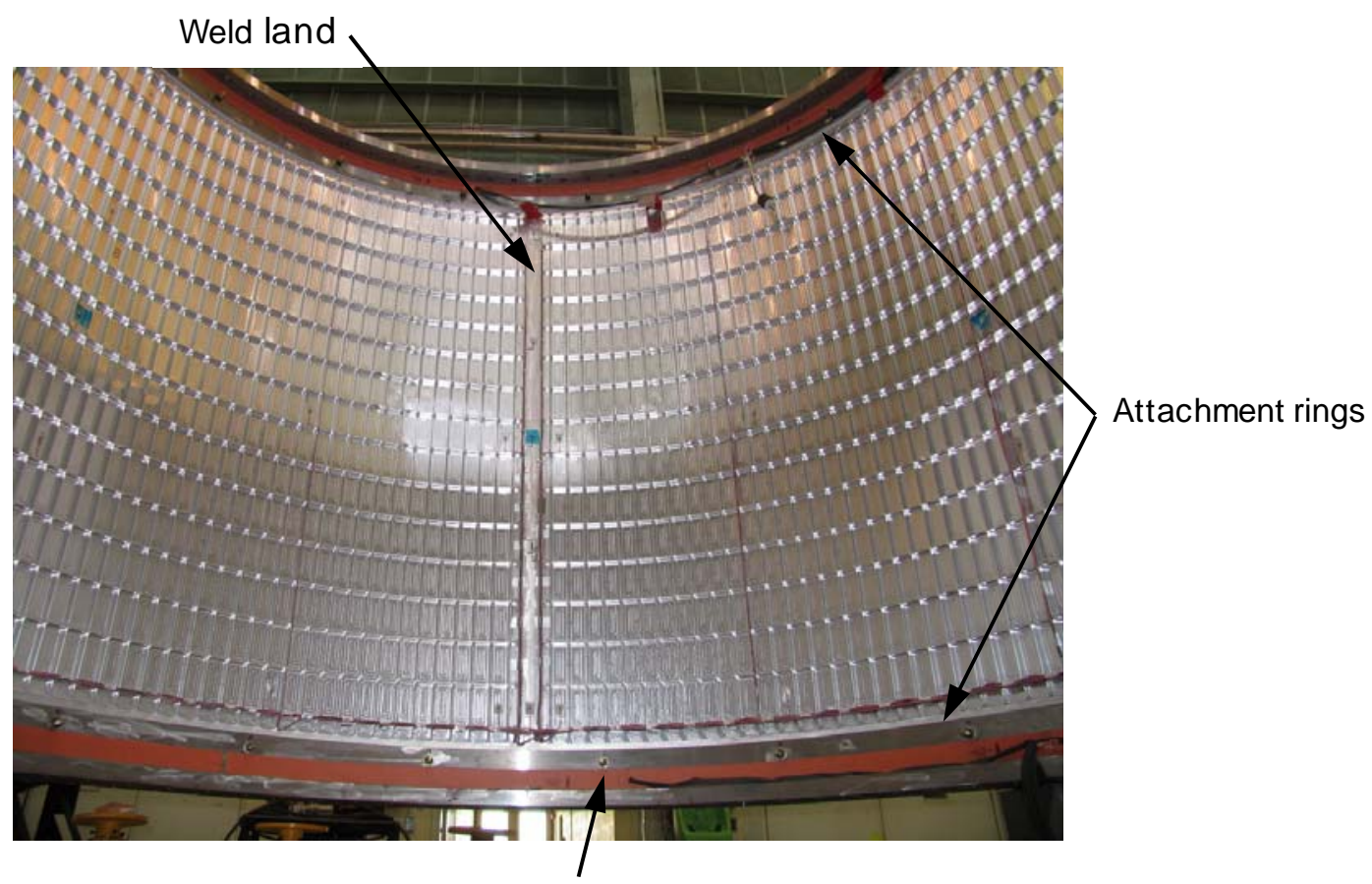

Fail-safe bolt (typ.)

Figure 7. Internal view of a typical orthogrid-stiffened cylinder test article, including a longitudinal weld land detail and attachment rings.

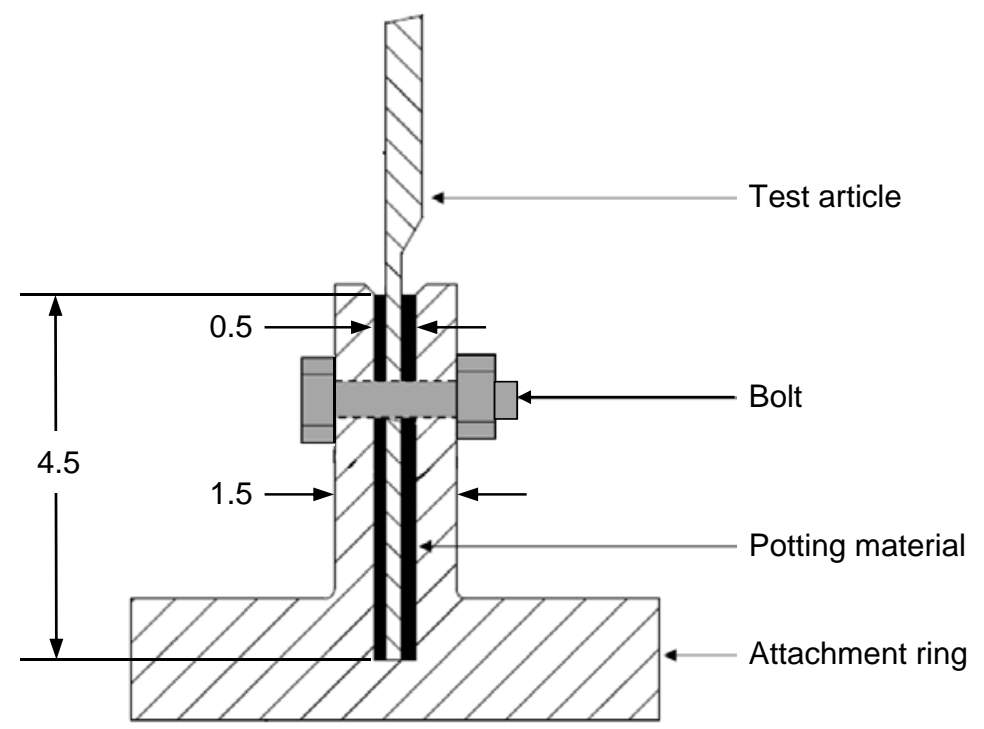

Figure 8. Attachement ring cross-section (dimension are in inches).

American Institute of Aeronautics and Astronautics 


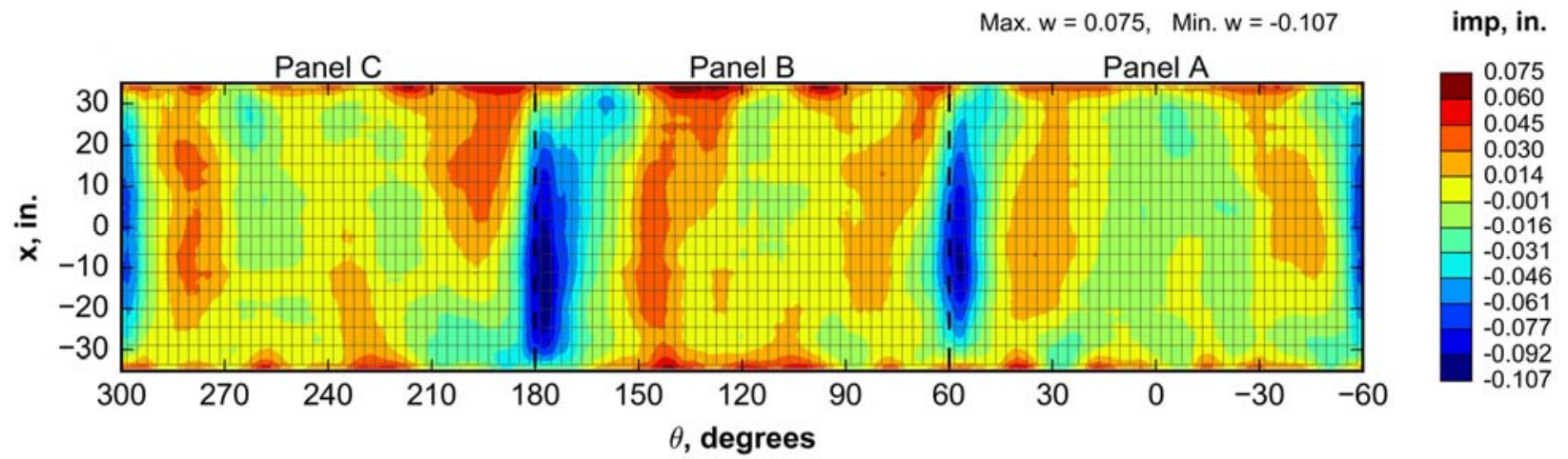

Figure 9. Measured geometric imperfection of TA07 (blue and red contours correspond to inward and outward radial imperfections, respectively).

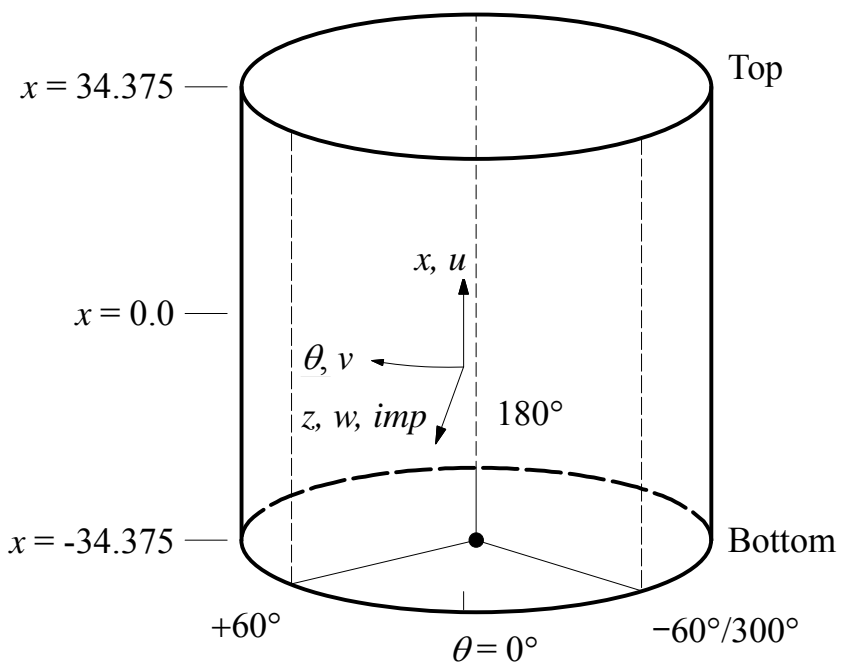

Figure 10. Coordinate system and displacement definitions. Vertical dashed lines indicate the location of longitudinal weld lands. Axial dimensions (given in inches) correspond to the nominal unsupported length of the cylinder.

\section{Test Facilities}

A shell buckling test facility was developed by SBKF for testing 8-ft-diameter cylinders subjected to combined axial compression, bending, and internal pressure, shown in Fig. 11. This facility is comprised of the test apparatus (shown in the figure), MTS FlexTest 60 multi-channel load control system, and custom-built 1000-channel data acquisition system.

The test apparatus was a self-reacting system comprised of two loading spiders, struts, two transition cylinders, and eight load lines. Each of the load lines were comprised of a hydraulic actuator, a 4-in-diameter loading rod, and a load cell. These load lines connect the upper and lower loading spiders. The 8-ft-diameter test article was attached between the upper and lower transition cylinders via the potted attachment rings. The test apparatus can apply a maximum compression load of 1.5 million $\mathrm{lbf}$ and an internal pressure load of $10 \mathrm{psi}$. Each of the components of the test frame were designed and analytically verified to ensure uniform loading into the test article. 


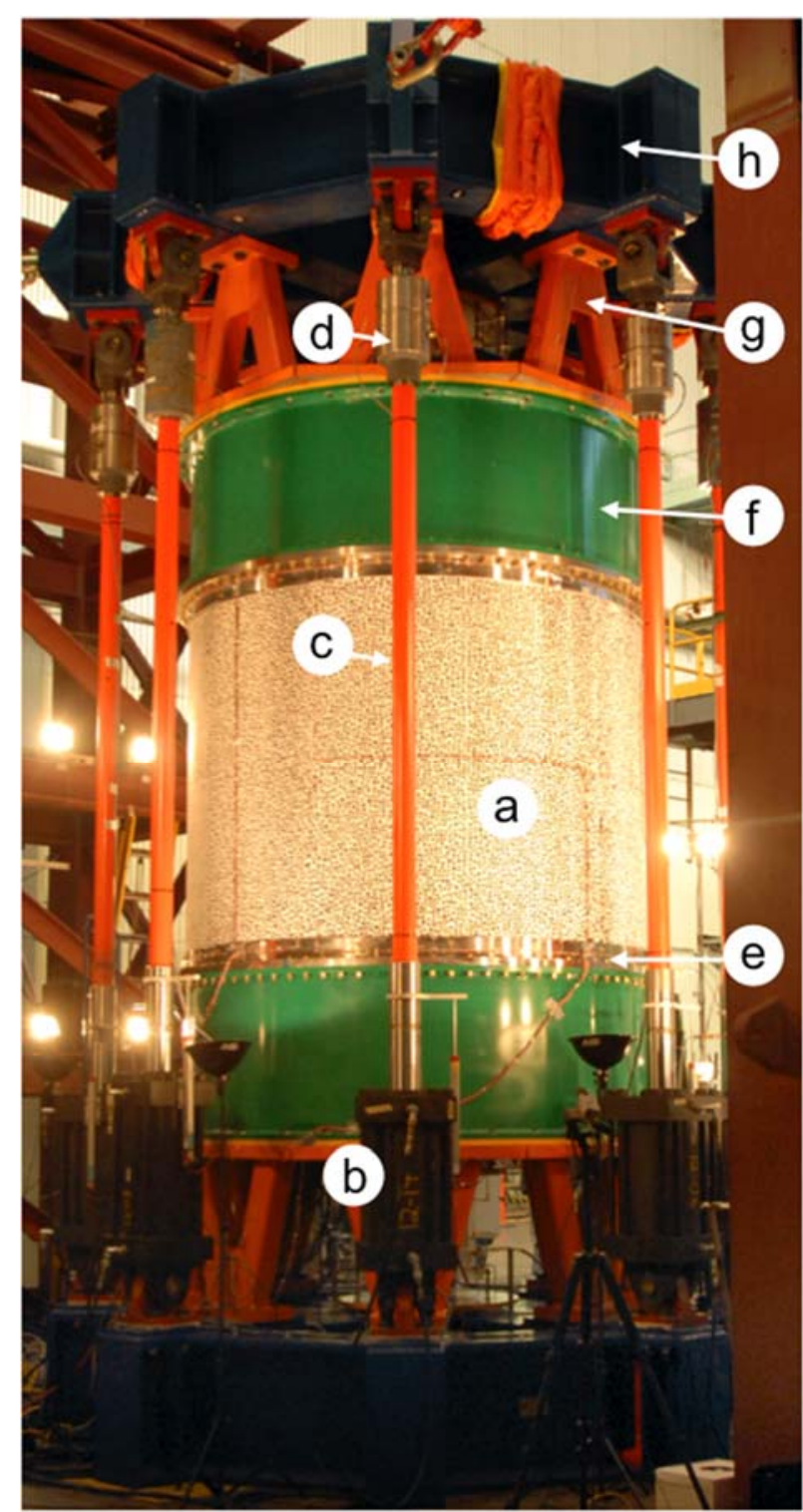

Figure 11. Eight-foot-diameter shell buckling test facility at NASA Marshall Space Flight Center (MSFC): a) test article, b) hydraulic actuator, c) loading rod, d) load cell, e) attachment ring, f) transition cylinder, g) load strut, and h) loading spider.

\section{Instrumentation}

Test article strains and displacement were measured using a combination of electrical resistance strain gages, linear voltage displacement transducers (LVDTs), and full-field digital image correlation (DIC). The subscale test articles had up to 324 strain gages to help characterize the strain response in the skin, stiffeners, and weld lands. Up to 25 LVDTs were used to measure the axial end-shortening displacements and radial displacements of the test article.

Low-speed and high-speed DIC systems were positioned around the circumference of the test article to measure the quasi-static and dynamic displacement response of the outer surface of the cylinder during testing. The low-speed DIC systems were used to measure the quasi-static prebuckling and postbuckling response, capturing images at 0.2 Hz. The high-speed cameras were used to measure the unstable transient buckling response, and captured images at $5000 \mathrm{~Hz}$. 


\section{Modeling and Analysis Methods}

Buckling analyses of the test articles were performed using the general-purpose finite element code Abaqus ${ }^{7}$. These finite element models included representations of the entire test assembly shown in Fig. 12, including the load introduction structure (loading spiders, struts, and transition sections, load lines), test article attachment rings, and the test article. The load introduction structure was included in the analysis to ensure that the boundary stiffness and kinematics were accurately modeled.

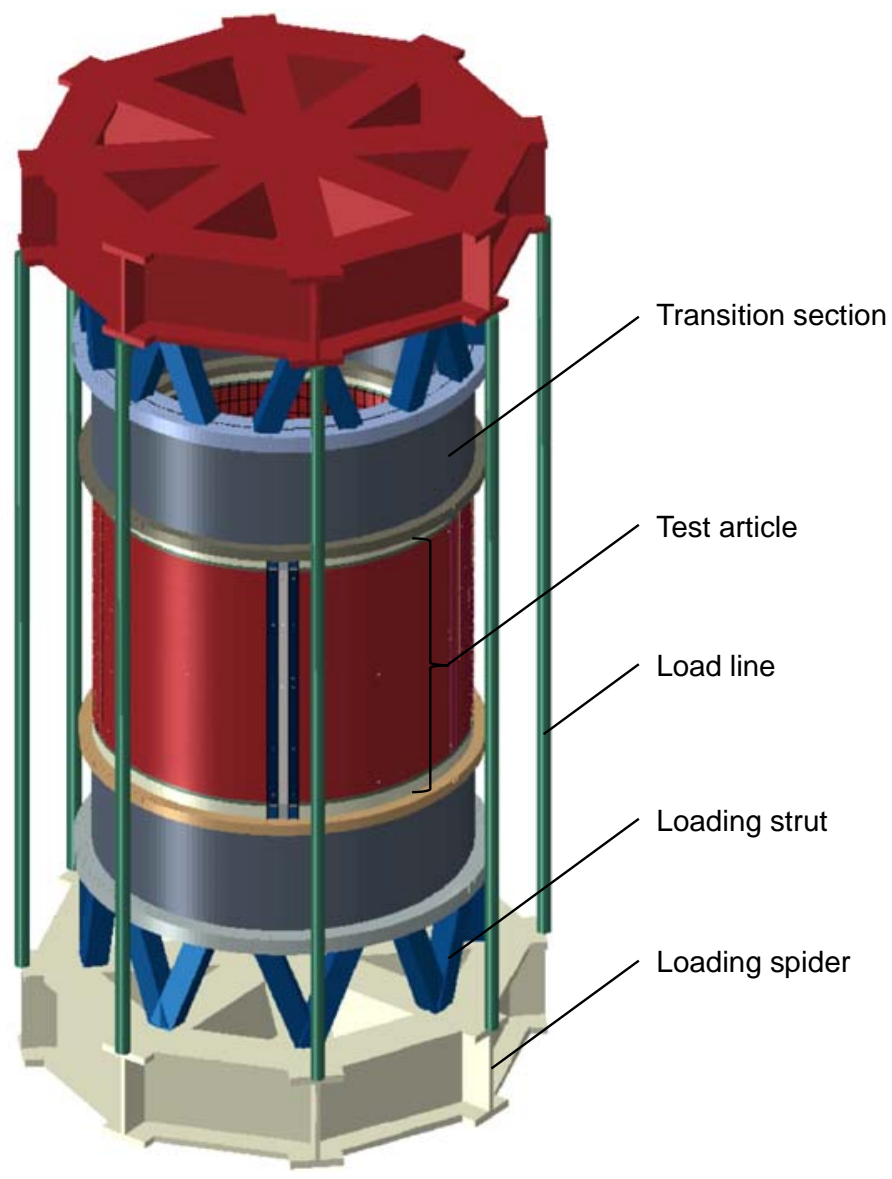

Figure 12. A rendering of a typical finite element model of the test assembly.

Preliminary test article models were developed based nominal geometry, material properties, and idealized boundary conditions. These models were used to generate pretest predictions of the buckling response and help define testing and instrumentation requirements. The basic structural dimensions for the othogrid and isogrid cylinders are given in Tables 1 and 2. The cylinder models included accurate representations of the skin, stiffeners, weld lands, and weld land transitions, including as-designed thickness variations and skin midsurface offsets. However, fillets and the complex stiffener geometry at the weld land transitions were neglected.

The standard Abaqus S4R quadrilateral shell element was used to model the test article skin and stiffeners, and is a four-noded flat facet-type element with reduced integration. The mesh reference surface was defined at the inner mold line (IML) of the test article and enabled straightforward accurate definition of the skin and stiffener geometry, and connectivity in locations where the skin thicknesses change. Detailed views of a typical finite element mesh of an orthogrid-stiffened cylinder are shown in Fig. 13. A notional OML location is shown in the figure to help accentuate the positioning of the mesh reference surface. The skin thickness in the test article changes as the acreage transitions into the weld lands, as illustrated in Fig. 3. This skin thickness change results in two discrete step changes in the radial position of the mesh reference surface, and can be seen in Fig 13a as gaps in the mesh. Connectivity across these 
discontinuities in the mesh was enforced by using rigid element connections between each node pair across the gap. Finally, the as-measured initial TA imperfection (e.g., Fig. 9) was used to modify the geometrically-perfect nominal geometry of the test article mesh to accurately represent the as-built geometrically-imperfect TA. Specifically, a userwritten subroutine was used to read in the measured imperfection data, and adjust the radial location of the finiteelement mesh at each nodal location of the skin. The stiffener nodal locations were also adjusted so as to maintain the as-designed height.

Mesh convergence studies were used to determine the mesh refinement requirements. The stiffeners were modeled using four elements along the height of the stiffener. The number of elements within each skin pocket varied from design to design, but typically had seven or more elements across the width of the pocket. The potted ends of the test article were modeled as a laminate, and included separate layers for the inner and outer steel attachment ring flanges, the potting material, and the test article. The transition cylinders were modeled using Abaqus S4R shell elements. The load lines, loading struts, and loading spiders were modeled using the Abaqus B31 beam element. The connections between each of the components of the test assembly were assumed to be uniform rigid attachments, with no relative movement between each component.

Al-Li 2195-T8M4 material properties used in the test article model were assumed to be linear elastic and isotropic with a Young's modulus of $11.0 \mathrm{Msi}$, a Poisson's ratio of 0.33 , and a density of $0.098 \mathrm{lbm} / \mathrm{in}^{3}$. It is known that this Al-Li material exhibits slight differences in the longitudinal and transverse stiffness properties. ${ }^{8}$ This difference was not considered in the preliminary models. The potting material was assumed to have a modulus of $1.0 \mathrm{Msi}$, and a Poisson's ratio of 0.3. A36 steel properties were used for all the test fixture components, and included an elastic modulus of $29.0 \mathrm{Msi}$, a Poisson's ratio of 0.26 , and a density of $0.28 \mathrm{lb} / \mathrm{in}^{3}$.

The load was introduced into the structure by applying eight point loads at the ends of the load line beam elements, and the bottom-loading spider was held fixed at a central node at its base. The buckling response of the cylinder was predicted using a two-step process. First, the prebuckling response was predicted using the standard Newton-Raphson, geometrically nonlinear static analysis up to the buckling load of the cylinder. Then, the unstable buckling response was predicted using a geometrically nonlinear dynamic analysis. The dynamic analysis was initiated from a stable prebuckling equilibrium state close to the limit point, and continued through the buckling event and into the postbuckling range of loading under displacement control. The dynamic analysis used mass-stiffness proportional damping and implicit numerical time integration. 


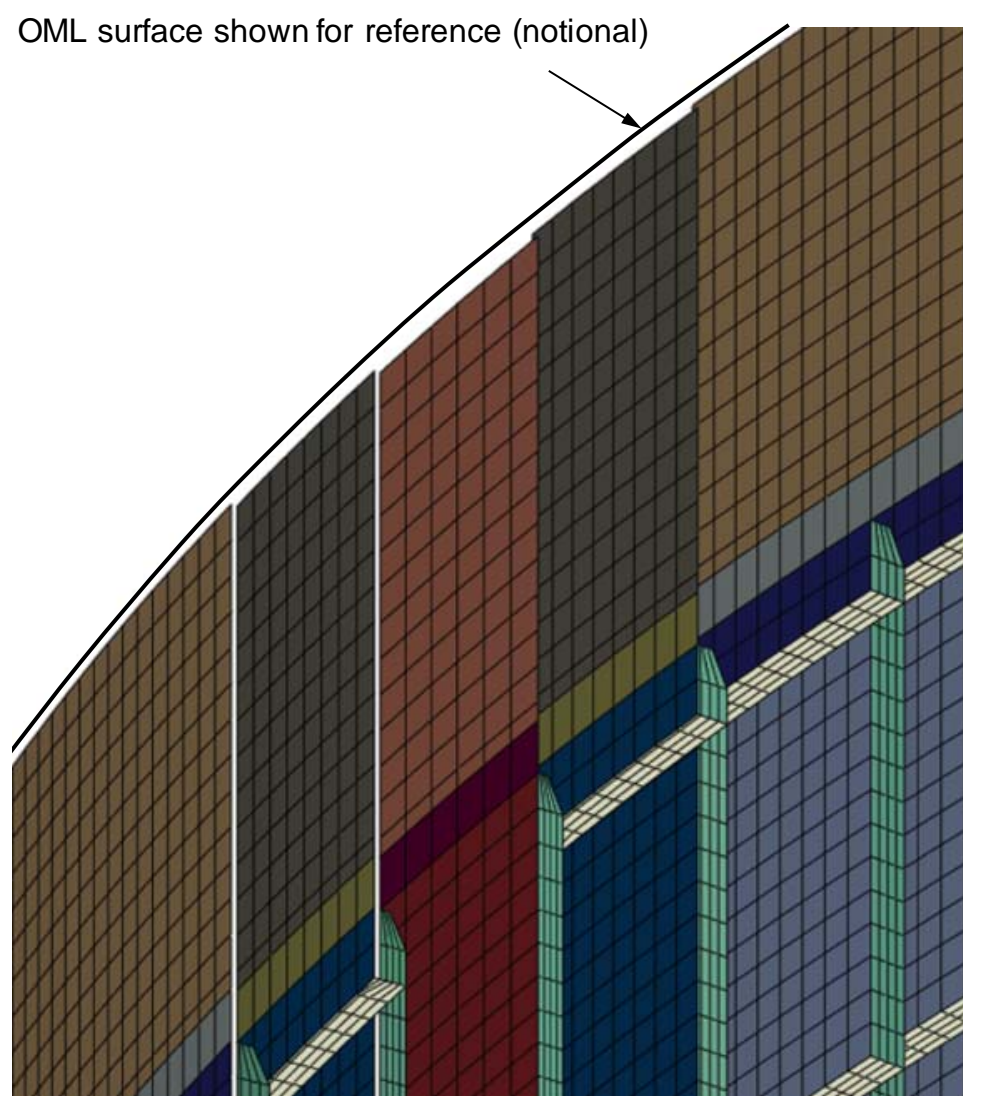

a) Isometric view of a typical test article mesh weld land, transition, and acreage mesh detail

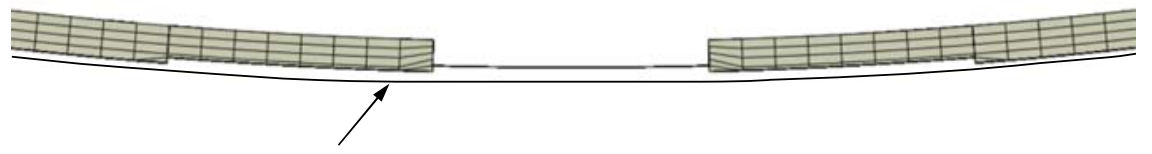

OML surface shown for reference (notional)

b) Cross-section view of an axial weld land, transition, and acreage mesh detail

Figure 13. Typical physical offset modeling approach.

\section{Test and Analysis Correlation}

Selected test and analysis results from a compression-loaded, orthogrid-stiffened test article, TA07, are presented to illustrate the typical buckling behavior of the 8-ft-diameter metallic cylinders tested by SBKF, and to highlight the modeling details and refinements necessary to develop highly accurate predictions of their buckling response. To this end, the test results are compared to pretest predictions first. These pretest predictions are based on the modeling approach described in Section III. Then, results from a model sensitivity study are presented and several model refinements are identified. Finally, results from an updated finite element model are presented and compared with the test results.

\section{A. Pretest Predictions and Test Results}

Predicted and measured axial load versus end-shortening response curves for TA07 are shown in Fig. 14. The test article exhibited a linear response up a maximum load of $647.0 \mathrm{kips}$ at which point, buckling initiated and the cylinder collapsed. Upon buckling and collapse, the cylinder experienced a 51.7\% reduction in axial load to a stable post- 
buckling load level of 312.2 kips. During the transient collapse event, the test article underwent a rapid increase in end-shortening from $0.12 \mathrm{inch}$ to $0.19 \mathrm{inch}$, and is attributed to the unloading response of the load introduction structure that imparted a sudden additional end-shortening displacement onto the test article. The predicted load-endshortening curve indicated a similar linear prebuckling response, but achieves a buckling load of $554 \mathrm{kips}, 14.4 \%$ less than the measured result. In addition, the predicted results indicated a similar increase in end-shortening during the transient collapse event.

Measured prebuckling, incipient buckling, and post-buckling radial displacement contours are shown in Fig. 15 and correspond to points $\mathrm{a}, \mathrm{b}$, and $\mathrm{c}$ on the load end-shortening plot in Fig. 14. The prebuckling deformations, shown in Fig. 15a, are characterized by local inward radial displacements along each of the three weld lands, and alternating regions of inward and outward radial displacements within each of the panel segments. As the cylinder approached the buckling load at point $b$, the inward radial displacements in the $B / C$ weld land begin to localize into a single dimple near the bottom attachment ring, as shown in Fig. 15b. Upon buckling, additional buckles formed around the entire circumference of the cylinder, resulting in the overall collapse of the structure, shown in Fig. 15c, and corresponding to point $\mathrm{C}$ in Fig. 14.

Predicted prebuckling, incipient buckling, and initial post-buckling displacement contours are presented in Fig.16 correspond to points $a^{\prime}, b^{\prime}$, and $c^{\prime}$ in Fig. 14. The displacement contours exhibit similar characteristics as the measured contours shown in Fig 15. In particular, the prebuckling response is characterized by local inward radial displacements along each of the three weld lands, and alternating regions of inward and outward radial displacements within each of the panel segments as shown in Fig. 16a. As the cylinder approached the buckling load, inward radial displacements began to localize into a single dimple near the bottom of TA07 in the A/B weld land, as shown in Fig. 16b. Upon, buckling, additional buckles formed around the entire circumference of the cylinder, corresponding to the overall collapse of the structure as shown in Fig. 16c, corresponding to point c' in Fig. 14.

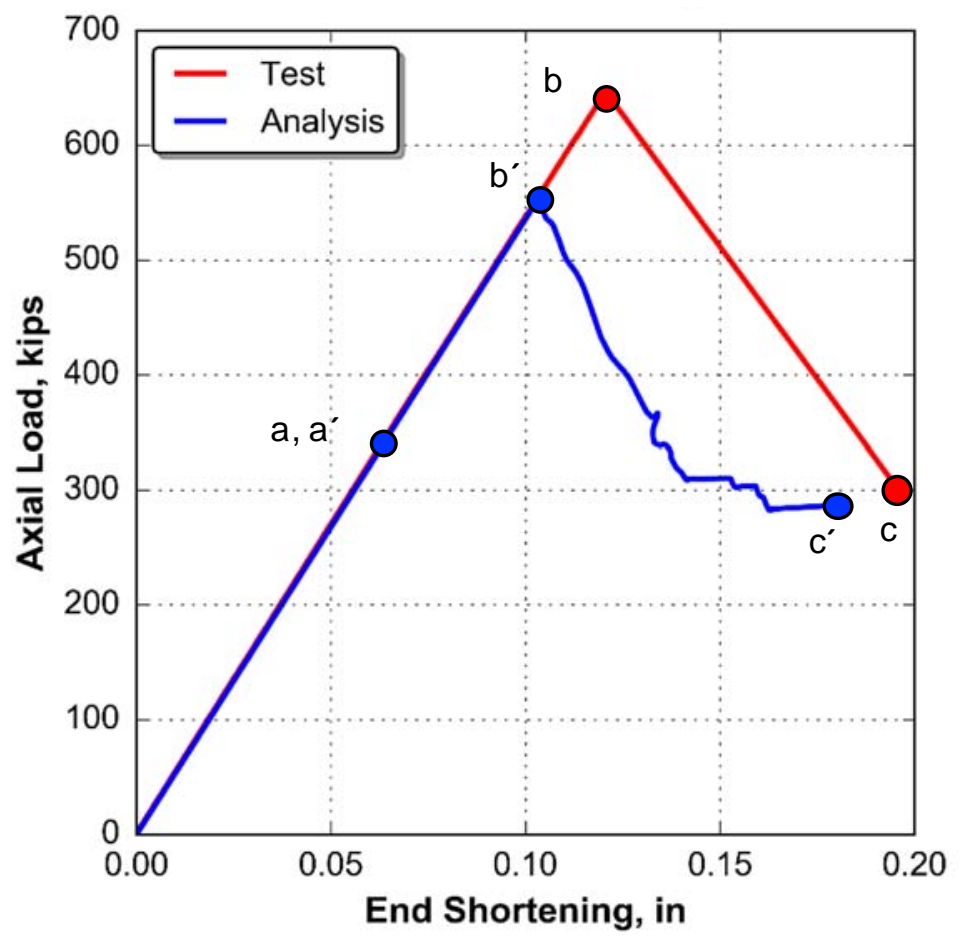

Figure 14. Predicted and measured load versus end-shortening response curves for TA07. 


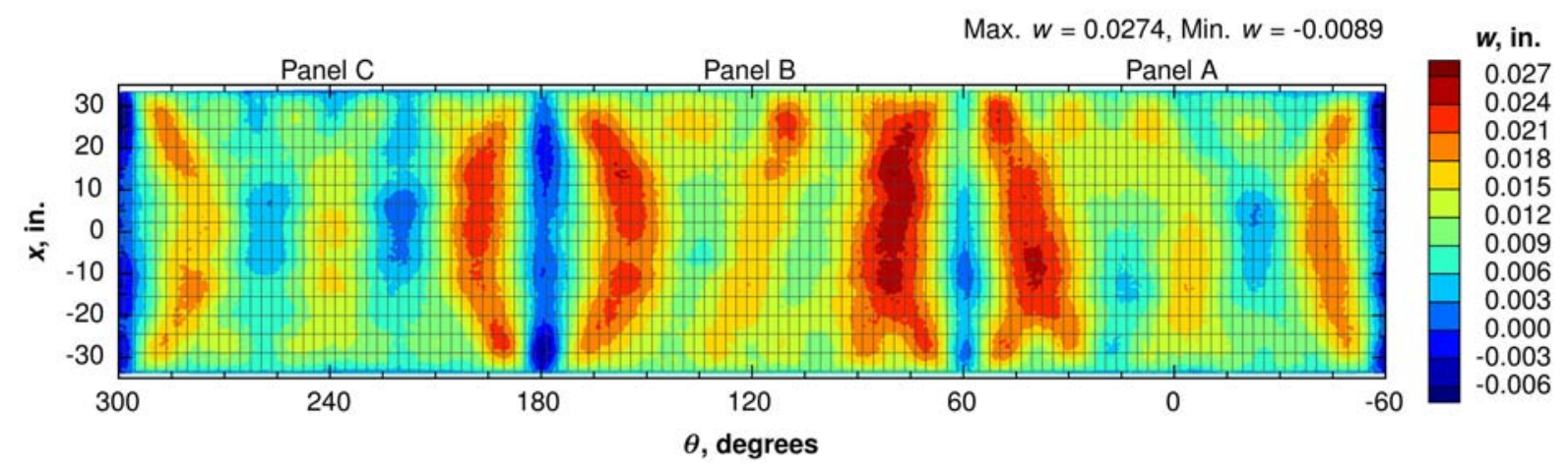

a) Measured, 337.1 kips, point a

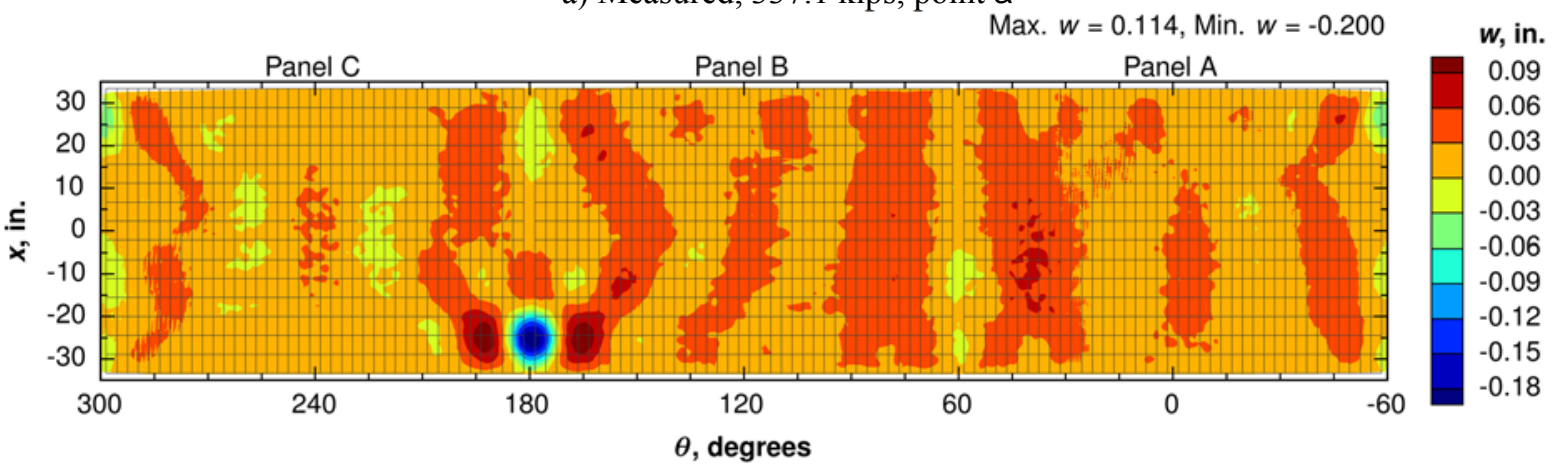

b) Measured, 647.0 kips, point $b$

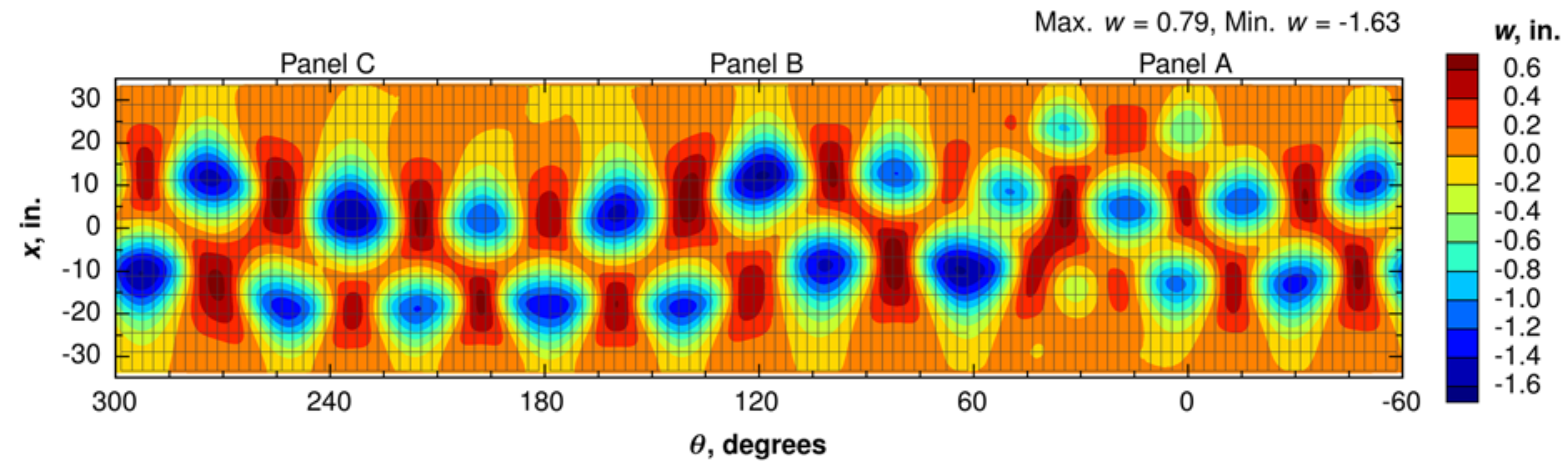

c) Measured, $312.2 \mathrm{kips}$, point C

Figure 15. Measured prebuckling (point a), incipient buckling (point b), and postbuckling (point c) radial displacements for TA07. 


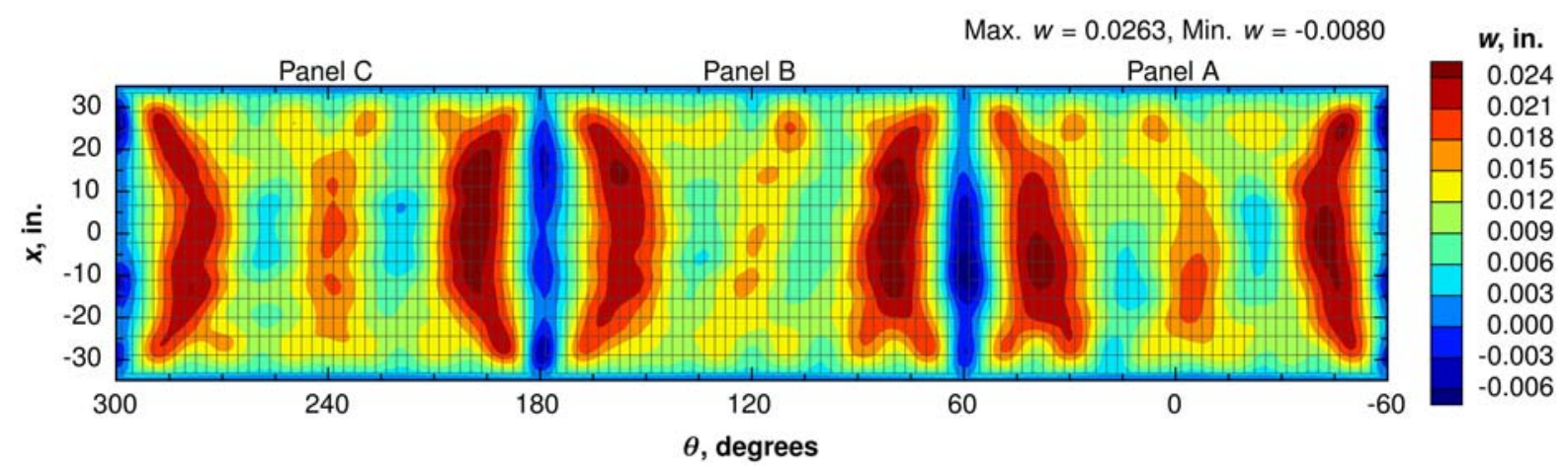

a) Prebuckling, 337.1 kips, point á

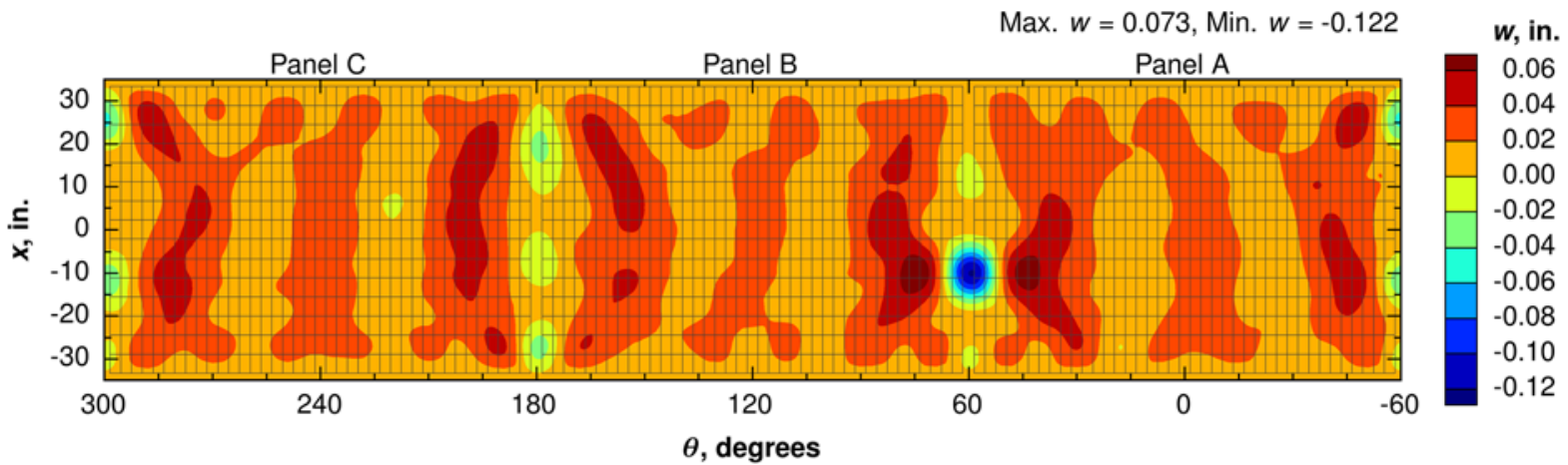

b) Incipient buckling, 554.0 kips, point b'

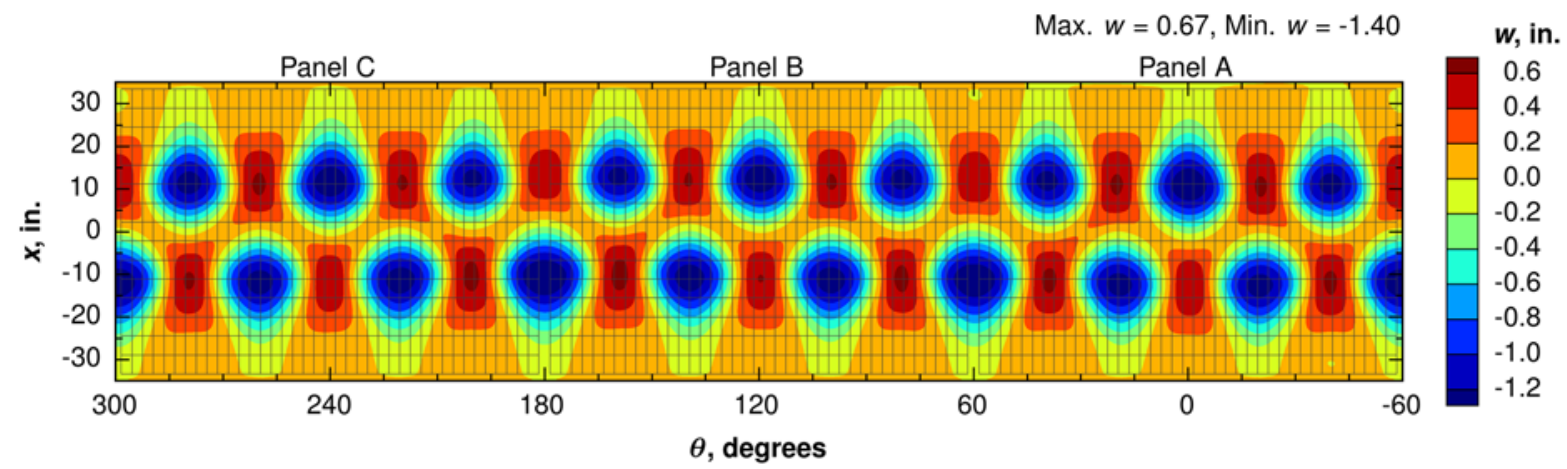

c) Postbuckling, 287.3 kips, point c'

Figure 16. Predicted prebuckling, incipient buckling, and postbuckling radial displacements for TA07.

Typical load versus radial displacement response curves are presented in Fig. 17 and include LVDT data (solid red curves), DIC data (red circle symbols), and pretest predictions (solid blue curves) from the center of panel C and the center of weld B/C. The DIC data was extracted from the full-field data at a point corresponding to the LVDT measurement location. The predicted load versus radial displacement response at the center of panel $\mathrm{C}$ correlated relatively well and is within $11 \%$ of the LVDT measurement. However, a significant discrepancy exists between the predicted and measured displacement response at the center of weld B/C. This discrepancy in the weld land displacements was observed in several of the SBKF test articles.

Finally, predicted and measured incipient buckling radial displacement traces from weld $A / B$ and weld $B / C$ are presented in Fig. 18. The predicted data is shown as solid blue curves and the measured DIC data is shown as dashed red curves. The predicted data includes results from the entire length of the cylinder, including regions potted in the upper and lower attachment rings. The measured DIC data was obtained from the visible cylinder OML surface. Overall, the predicted and measured results appear to share similar behavioral characteristics in terms of the number 
of axial half-waves present in the displacement response. However, the results clearly highlight the different buckling initiation points.

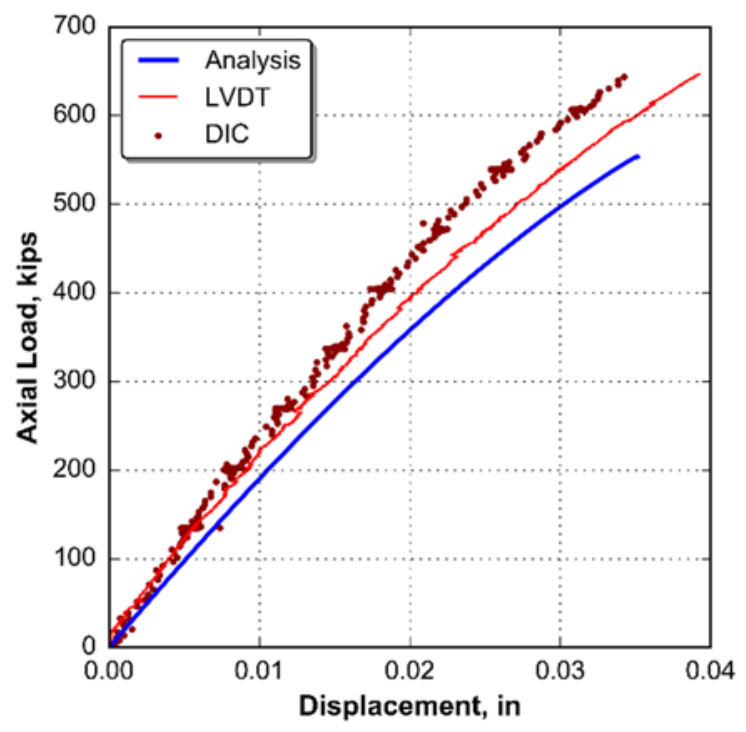

a) Center of Panel C

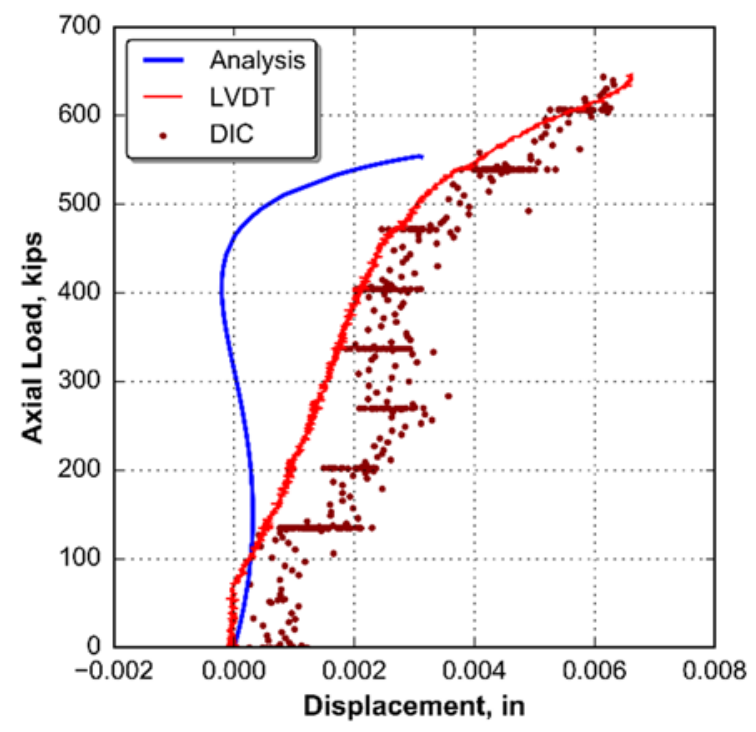

b) Center of $B / C$ weld

Figure 17. Predicted and measured load versus radial displacement curves for TA07.

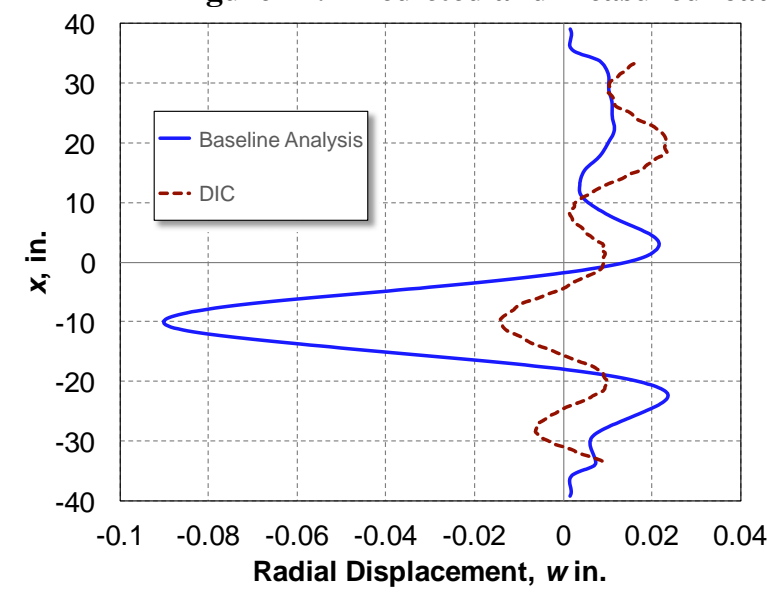

a) Weld $A / B$

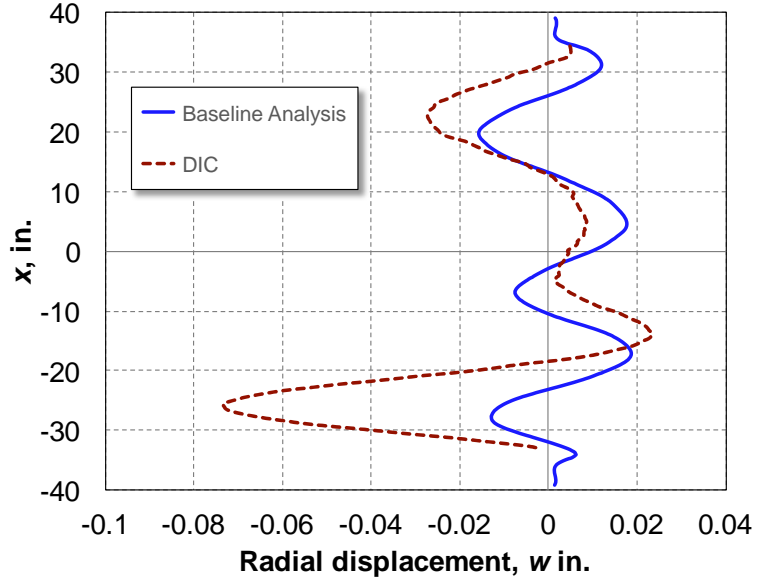

b) Weld B/C

Figure 18. Predicted and measured radial displacement traces along the $A / B$ weld and the $B / C$ weld.

In summary, the pretest analysis results provide a good qualitative prediction of the nonlinear and buckling response of TA07. In particular, the prebuckling load-end-shortening response, radial displacement contours, and load versus radial displacements at the center of the cylinder panel sections typically show good correlation. However, the predicted buckling load and overall character of the displacement response at the axial weld lands do not correlate as well. Similar results were obtained for the other seven 8-ft-diameter metallic cylinders in the SBKF test program and suggest that some modeling refinement was required to obtain the highly accurate buckling predictions necessary to develop analysis-based design data. To this end, a comprehensive sensitivity study was performed to assess some of the modeling assumptions, and identify the modeling refinements needed to improve the predicted results. Results from this sensitivity study on TA07 are presented next.

\section{B. Sensitivity Study}


A sensitivity study was performed to determine the effects of several different modeling assumptions on the predicted response of TA07. The assumptions studied include Young's modulus, as-built skin and stiffener geometry, boundary conditions, initial geometric imperfection shape and amplitude, fillet details, and loading nonuniformities. A summary of the pretest modeling assumptions and the modeling adjustments considered are presented in Table 3 . In addition, changes in the cylinder response (e.g., buckling load, effective axial stiffness, buckling location) are noted. Each modeling adjustment was applied individually and, as a result, interactions between the various assumptions were not characterized.

Table 3. Finite element model refinements

\begin{tabular}{|c|c|c|c|c|}
\hline Model detail & $\begin{array}{l}\text { Pretest model } \\
\text { assumption }\end{array}$ & Model adjustment & $\begin{array}{c}\text { Change in } \\
\text { buckling load }\end{array}$ & Other \\
\hline $\begin{array}{l}\text { Young's } \\
\text { modulus }\end{array}$ & $\begin{array}{l}\text { Uniform } \\
\text { modulus, } \mathrm{E}= \\
11.0 \mathrm{Msi}\end{array}$ & $\begin{array}{l}\text { Separate compression and } \\
\text { tension modulus values, } \mathrm{E}_{\mathrm{c}}= \\
11.4 \mathrm{Msi}, \mathrm{E}_{\mathrm{t}}=10.8 \mathrm{Msi}\end{array}$ & $1.3 \%$ & $\begin{array}{l}2.5 \% \text { increase in effective } \\
\text { axial stiffness }\end{array}$ \\
\hline $\begin{array}{l}\text { Skin and } \\
\text { stiffener } \\
\text { thicknesses }\end{array}$ & $\begin{array}{l}\text { Nominal, as- } \\
\text { designed }\end{array}$ & $\begin{array}{l}\text { Use average measured } \\
\text { thicknesses. } t=0.093, t_{s}= \\
0.108, t_{r}=0.104\end{array}$ & $7.8 \%$ & $\begin{array}{l}4.4 \% \text { increase in effective } \\
\text { axial stiffness }\end{array}$ \\
\hline $\begin{array}{l}\text { Stiffener } \\
\text { heights }\end{array}$ & $\begin{array}{l}\text { Nominal, as- } \\
\text { designed }\end{array}$ & $\begin{array}{l}\text { Use average measured height, } \\
H=0.445\end{array}$ & $1.1 \%$ & None \\
\hline $\begin{array}{l}\text { Attachment ring } \\
\text { model }\end{array}$ & $\begin{array}{l}\text { Steel ring and } \\
\text { Al-Li cylinder } \\
\text { modeled as a } \\
\text { laminate }\end{array}$ & $\begin{array}{l}\text { Model rings as } \\
\text { circumferential beams to } \\
\text { provide radial constraint and } \\
\text { axial compliance }\end{array}$ & $<1.0 \%$ & $\begin{array}{l}6.3 \% \text { reduction in } \\
\text { effective axial stiffness } \\
\text { Change in bending } \\
\text { boundary layer response }\end{array}$ \\
\hline $\begin{array}{l}\text { Attachment ring } \\
\text { thru bolt detail }\end{array}$ & Neglected & $\begin{array}{l}\text { Bolt detail modeled using } \\
\text { rigid links }\end{array}$ & $1.6 \%$ & None \\
\hline $\begin{array}{l}\text { Geometric } \\
\text { imperfection }\end{array}$ & $\begin{array}{l}\text { White-light } \\
\text { geometry } \\
\text { measurement }\end{array}$ & $\begin{array}{l}\text { Measured imperfection } \\
\text { amplitude reduced to match } \\
\text { DIC-based pretest } \\
\text { measurement }\end{array}$ & $4.5 \%$ & None \\
\hline $\begin{array}{l}\text { Stiffener fillet } \\
\text { representation }\end{array}$ & Neglected & $\begin{array}{l}\text { Local stiffener thicknesses } \\
\text { increased based on } \\
\text { correlation between 2-D shell } \\
\text { model and 3-D solid model }\end{array}$ & $4.2 \%$ & None \\
\hline $\begin{array}{l}\text { Attachment ring } \\
\text { imperfection }\end{array}$ & Neglected & $\begin{array}{l}\text { Measured attachment ring } \\
\text { interface surface geometry } \\
\text { measured and included in } \\
\text { model }\end{array}$ & $-1.8 \%$ & $\begin{array}{l}\text { Change in buckling } \\
\text { location from weld land } \\
\mathrm{A} / \mathrm{B} \text { to weld land } \mathrm{B} / \mathrm{C}\end{array}$ \\
\hline
\end{tabular}

Young's modulus, skin and stiffener thickness, and stiffener height

The nominal Young's modulus was assumed to be $11.0 \mathrm{Msi}$, in tension and compression, and is a typical conservative design assumption used. However, heat treated T3 to T8 temper thin plate 2195 material, exhibits a tension modulus of $10.8 \mathrm{Msi}$ and a compression modulus of 11.4 Msi. Consequently, a cylinder subjected to axial compression, results in compressive strain in the axial direction and tensile strain in circumferential direction. Thus, it was convenient to define an orthotropic material model with the longitudinal Young's modulus equal to the compression modulus of $11.4 \mathrm{Msi}$ and the circumferential modulus equal to the tension modulus of $10.8 \mathrm{Msi}$. This modification resulted in an increased buckling load of $1.3 \%$ and an increased effective axial stiffness of $2.5 \%$.

Next, skin and stiffener thicknesses were increased to the average measured values obtained from postmanufacturing inspections of the test articles. The average measured values for TA07 include a skin thickness $t=$ 0.093 inch, axial stiffener thickness $t_{s}=0.108 \mathrm{inch}$, and average circumferential stiffener thickness $t_{r}=0.104$ inch. This modification increased the buckling load $7.8 \%$, and increased the effective axial stiffness $4.4 \%$. The stiffener height was increased to the average measured height of $\mathrm{H}=0.445$ inch, and increased the buckling load $1.1 \%$.

Boundary conditions - attachment ring and through-bolt detail 
It has been shown through previous studies that boundary conditions can affect the nonlinear and buckling response of compression-loaded cylinders. ${ }^{9}$ Specifically, elastic constraints in the axial and radial directions can have a significant influence on the effective axial stiffness and bending boundary layer response. The pretest models defined the potted attachment ring boundary condition by using a five-layer laminate. The inner and outer layers represented the steel attachment ring flanges, the middle three layers represented the stiffness of the TA, the potting material between the TA, and the attachment ring flanges. However, previous studies indicate that this type of boundary condition could be too stiff. ${ }^{9}$ In the sensitivity study, boundary conditions were developed to allow for unconstrained axial motion of the TA while maintaining a relatively stiff lateral constraint. This boundary condition was achieved by modeling the TA shell with nominal shell-wall thickness and stiffness, and then adding stiff circumferential rings at each row of nodes associated with the portion of the TA imbedded in the attachment rings. The application of this boundary condition is illustrated in Fig. 19. Rings denoted by the black dashed lines were given the properties of steel and the ring closest to the stiffened acreage, denoted by the gray dashed line, was given the properties similar to the potting material to allow for some radial flexibility that is likely to exist. The cross-section of each beam was 1.5 inches wide (thickness of the original laminate) with the depth of each beam being equal to the axial length of the attached TA shell elements, thus maintaining the overall attachment ring cross-sectional area. This modified boundary condition resulted in an insignificant change in the buckling load, but reduced the effective axial stiffness of the cylinder by $6.3 \%$ due to the additional compliance. This modification in boundary stiffness also resulted in a significant change in the displacement response in the axial weld lands. In particular, axial traces of the radial displacement response along weld lands A/B and B/C are shown in Fig. 20, and indicate as much as 120\% increase in the outward radial displacements in the bending boundary layer. Furthermore, the modified boundary condition can lead to a significant change in the overall character of the displacement response as shown in Fig 20a for weld land $\mathrm{A} / \mathrm{B}$.

The TA assembly included a series of bolts through the attachment ring and potted ends of the TA, serving as a fail-safe attachment in case the potting failed during handling or testing. The effects of these bolts on the response of the TA were neglected in the baseline models. However, it is possible that these bolts support some of the axial compression load during the test, resulting in changes in load distribution into the TA. Thus, the effects of the bolts on the TA buckling response was investigated for several TAs. The effects of the bolts in the upper and lower attachment rings were simulated by applying rigid link elements between the loaded edges of the TA and a node in the TA mesh located at the bolt hole locations at $\theta=10^{\circ}, 30^{\circ}, 50^{\circ} \ldots 350^{\circ}$, denoted by the gray fill circles in Fig. 19. This modification resulted in a $1.6 \%$ increase in the buckling load, primarily due to a load redistribution from the weld lands into attachment bolts adjacent to each weld land (see bolt locations in Fig. 19). 


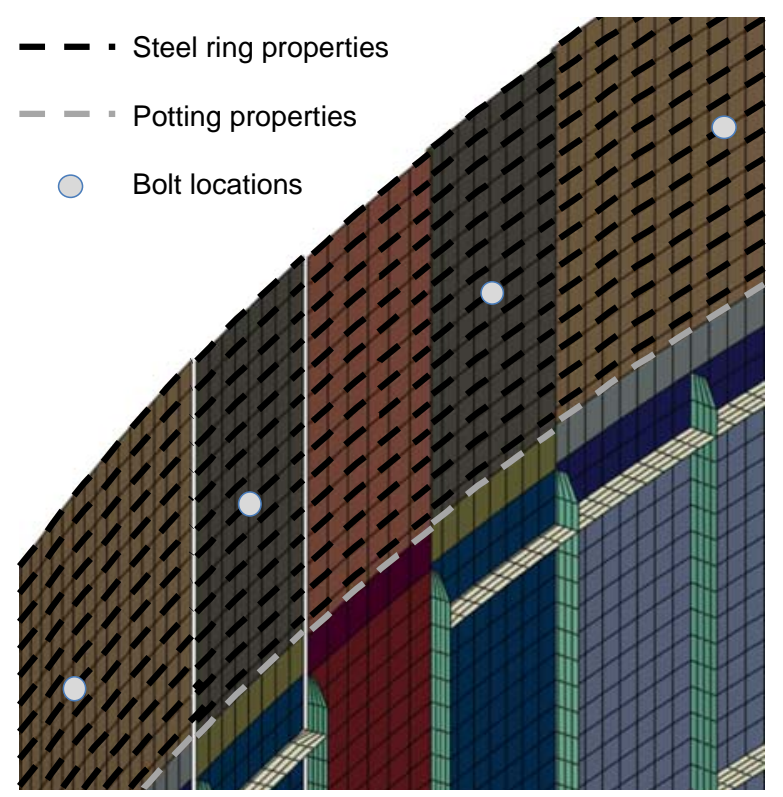

Figure 19. Isometric view of a typical test article mesh weld land, transition, and acreage mesh detail showing a typical modified boundary condition.

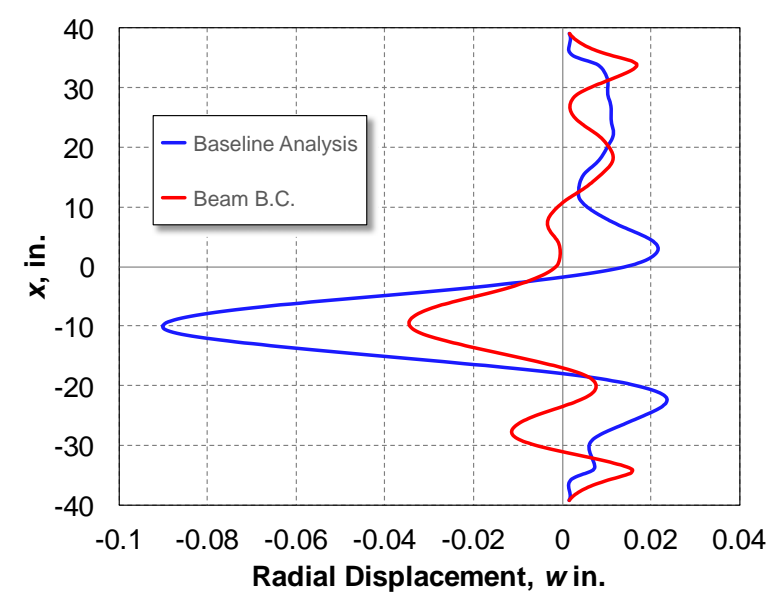

a) Weld A/B

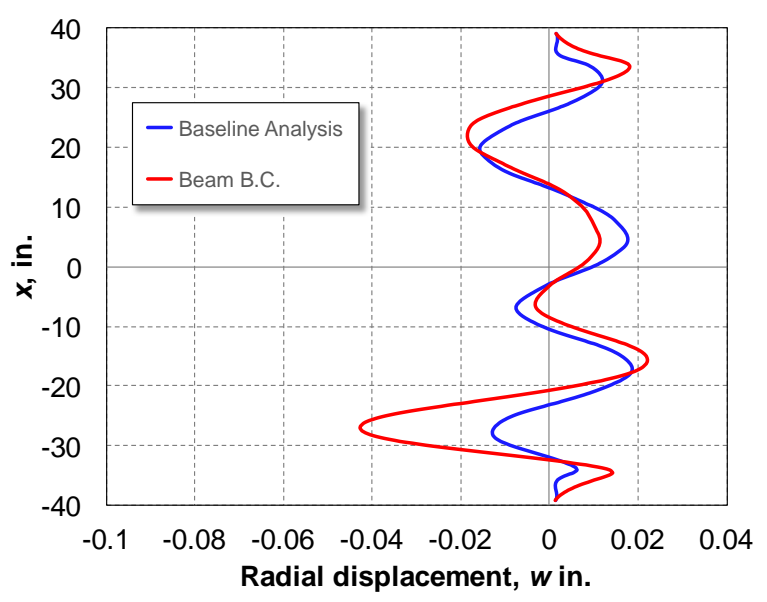

b) Weld B/C

Figure 20. Predicted radial displacements along weld $A / B$ and weld $B / C$ from the TA07 pretest model and model with modified attachment rings.

\section{Geometric imperfection}

Prior to test, the initial geometry of each test article was measured using DIC and compared to structured-lightbased imperfection measurement to identify any changes in the geometry that may have occurred during installation into the test facility. For example, the structured-light imperfection data for TA07 is shown in Fig. 9 and the corresponding DIC-based imperfection is shown in Fig 21a. The DIC measurement indicated that the overall imperfection shape was similar to the initial white-light measurement, with some slight differences near the bottom of the cylinder at the $200^{\circ}$ circumferential location. In addition, the magnitude of the imperfection at each of the weld lands was slightly less. These differences can be seen more clearly from a delta plot in which the structured-light imperfection data was subtracted from the DIC-based imperfection, as shown in Fig $21 \mathrm{~b}$. The delta plot indicates small changes in the imperfection amplitude, on the order of \pm 0.06 inch including small reductions in the imperfection amplitude at each weld. Based on this finding, the initial geometry of the TA07 cylinder model was adjusted to match the as-tested geometry measured using the DIC data. The modified imperfection increased the predicted buckling load by $4.5 \%$. 


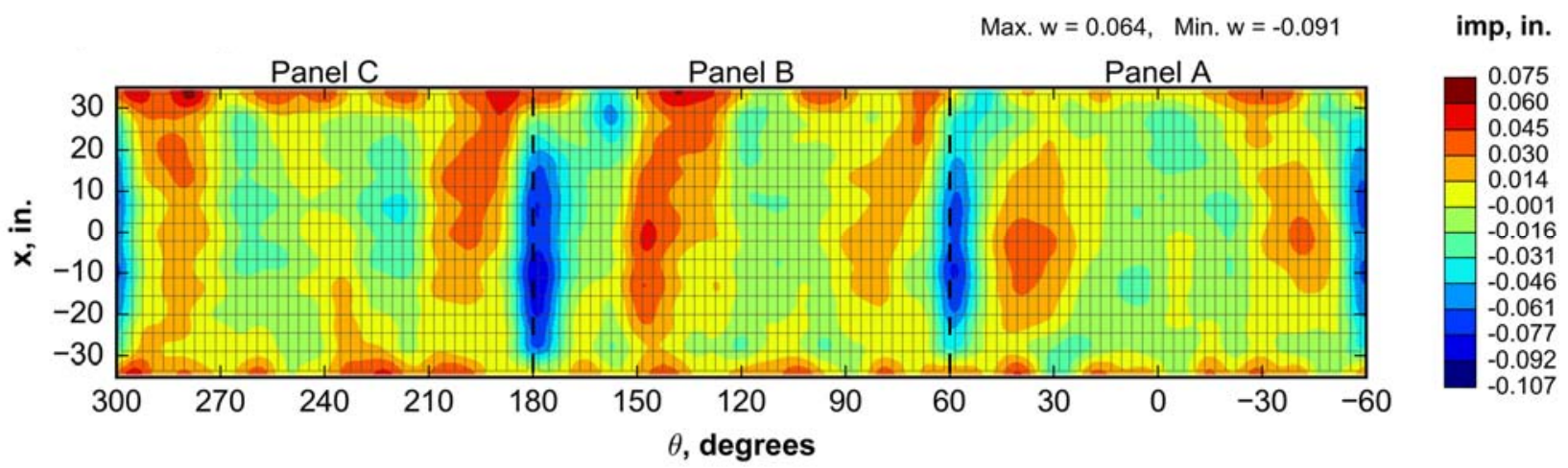

a) DIC-based initial geometric imperfection for TA07 as install in the test facility

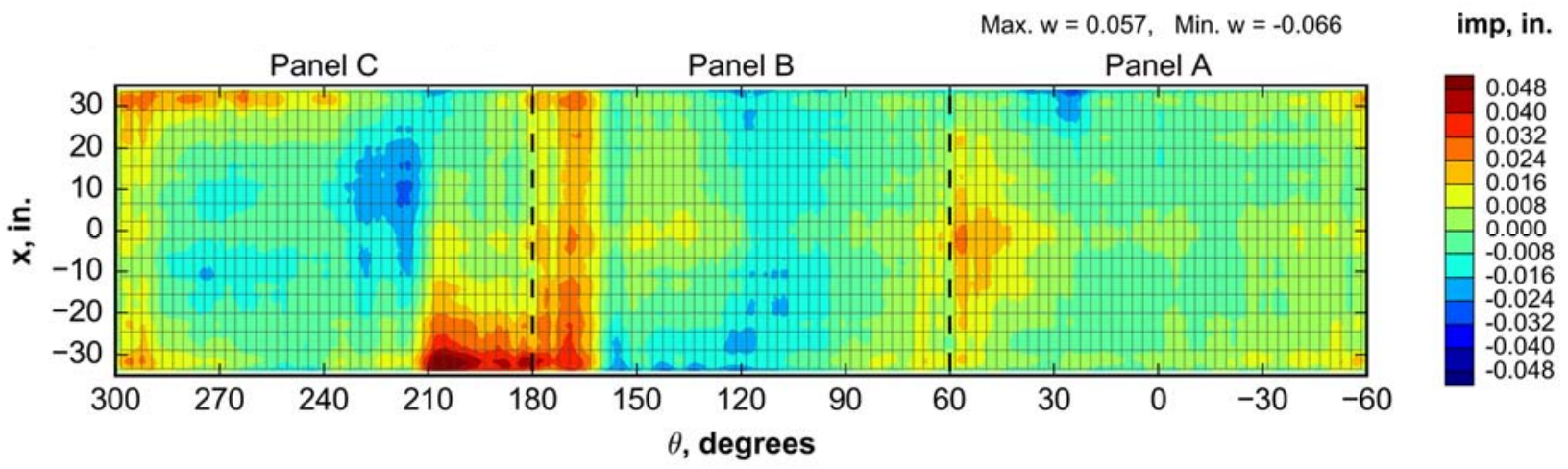

b) Delta plot between the structured-light-based geometric imperfection and the DIC-based geometric imperfection

Figure 21. DIC-based measured geometric imperfection and imperfection delta plot for TA07.

\section{Fillet details}

Typically, the effects of detail features such as fillets are omitted from models to reduce model complexity. However, these fillet details can provide additional support to the skin and the stiffeners, increase the effective axial stiffness of the cylinder, and affect the predicted buckling. In this study, representations of the fillets were added to the model by increasing local stiffener thickness near the intersection between the stiffeners and skin, and at the intersection between stiffeners to simulate the effects of the fillet details (see Figs. 1 and 2 for illustrations). To do so, a shell thickness tuning approach, based on correlations between two-dimensional (2D) shell models and threedimensional (3D) solid models, was used to develop an equivalent set of shell thickness properties to represent the fillets.

Shell and solid models were developed for selected test article subcomponents. A typical shell model of a subcomponent for TA07 is shown in Fig. 22 and includes acreage (indicated by the green skin elements), transition regions (indicated by the grey elements), and a weld land (indicated by the red elements). The shell subcomponent models were generated in Abaqus and used the same modeling assumptions and mesh refinement used in the full TA model, so that the thickness properties derived from the tuning process could be transferred directly to the TA model. A magnified view of a shell element mesh from a typical acreage model is shown in Fig. 23a. The different colored elements are associated with different element sets in the mesh in which the thicknesses properties can be defined. Corresponding subcomponent models were generated using solid elements, and included detailed representations of all the as-designed fillet features. A magnified view of a typical solid element model is shown in Fig. 23b. The solid models were created and analyzed using both Abaqus and Creo/Simulate. 


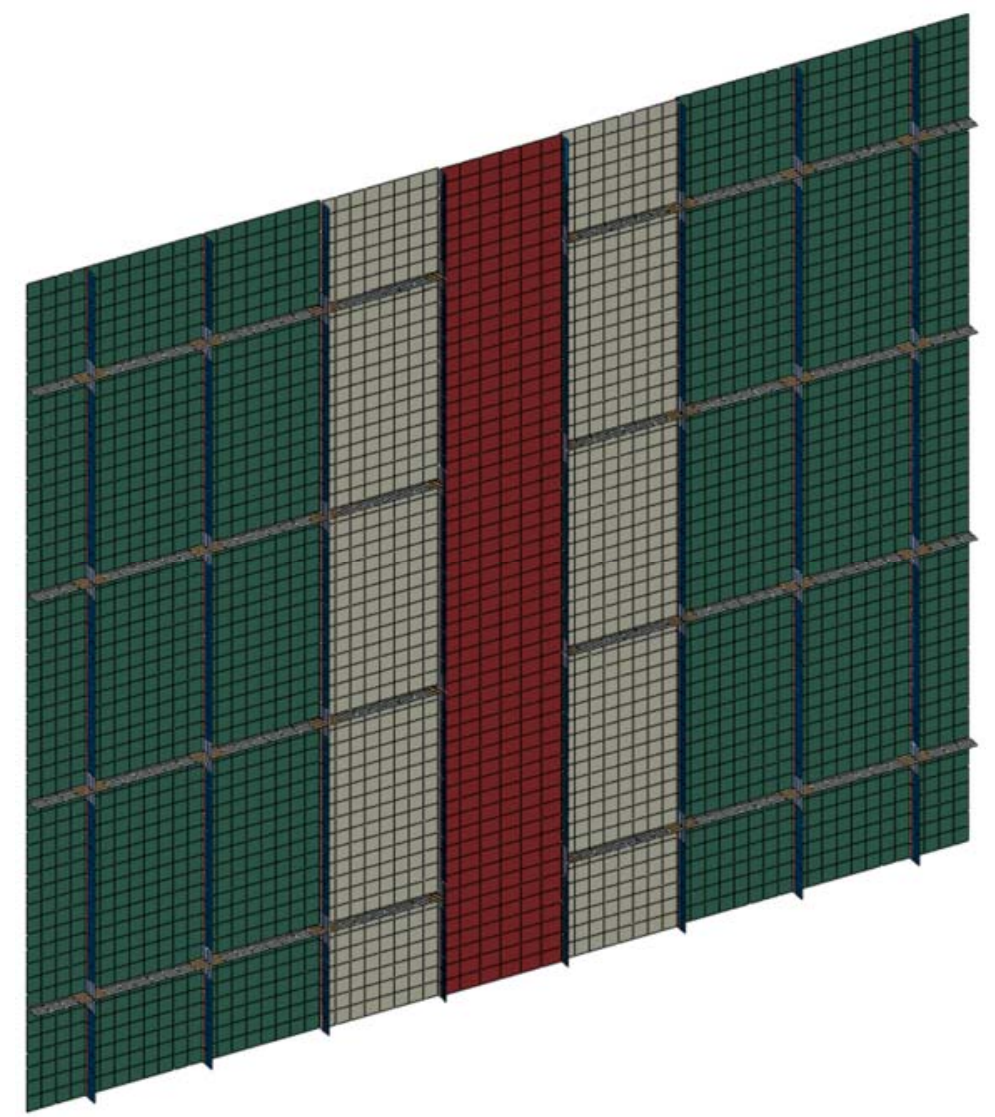

Figure 22. Typical shell model of a TA07 orthogrid subcomponent including acreage (green elements), transition regions (gray elements), and longitudinal weld land (red elements) details.

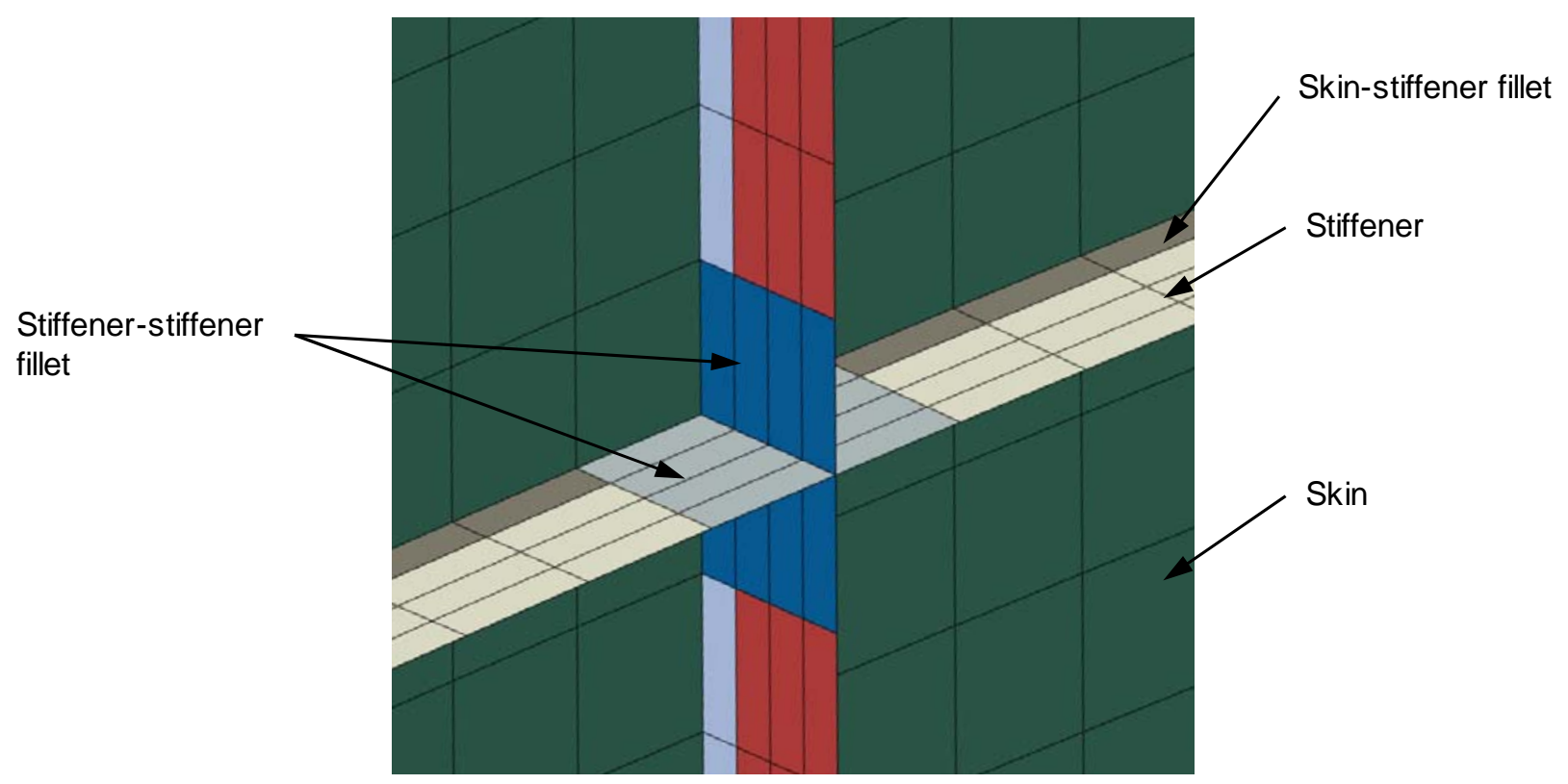

a) Shell model. 


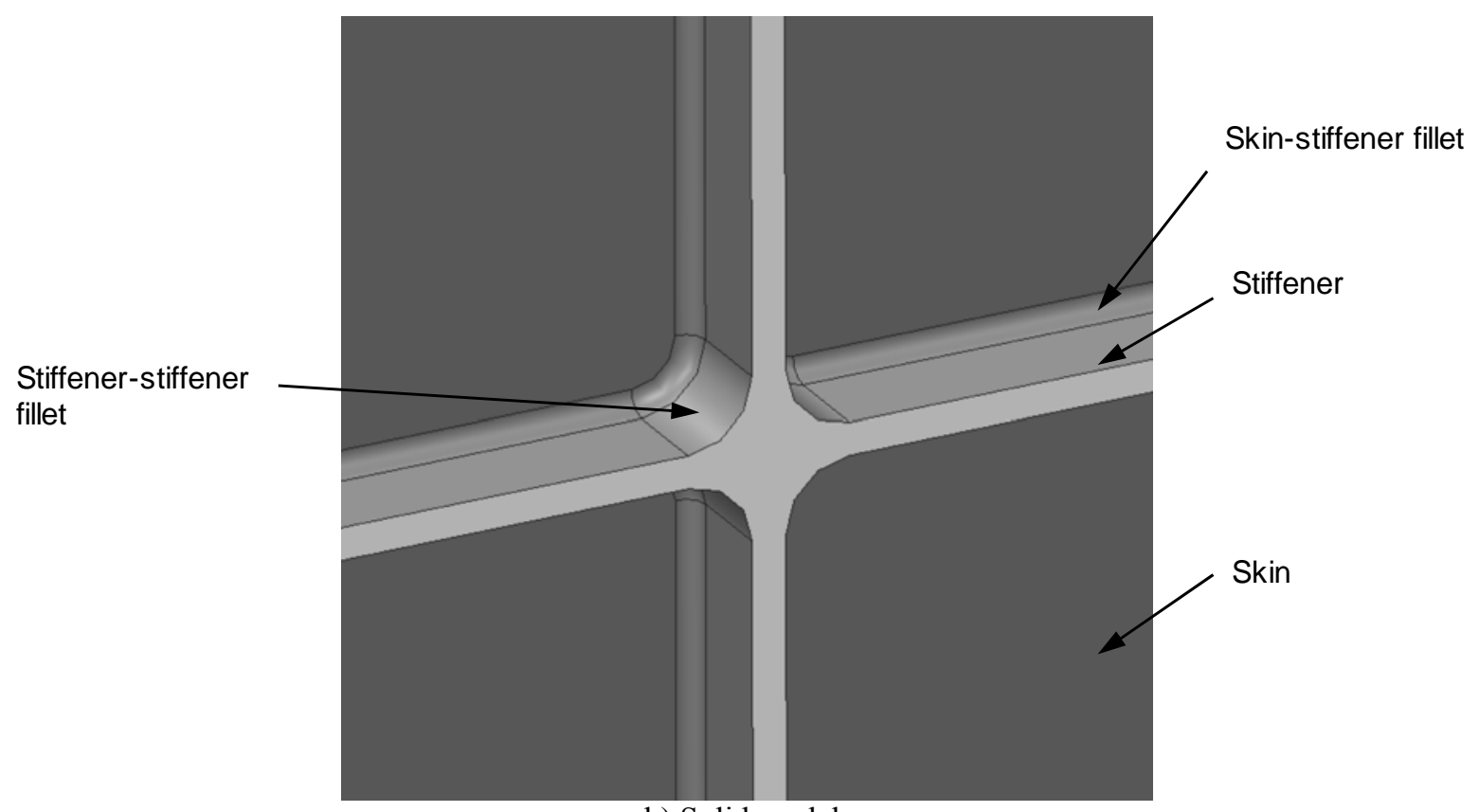

b) Solid model

Figure 23. Typical shell and solid models at the intersection between two stiffeners.

Linear eigenvalue analyses were conducted on the shell and solid models to produce a series of eigenmodes and loads. It was important that the predicted eigenmodes included both global panel buckling modes and local skin pocket buckling modes, so that both modal contributions would be factored into the adjustment of the shell model thickness properties. The models assumed simply-supported boundary conditions on all edges, and an axial compression load was applied to the subcomponent by imposing uniform end-shortening displacement on the top edge. An iterative process was used to adjust the shell model thickness properties in the fillet locations, until the shell model eigenloads and modes match the corresponding solid model results to within $\pm 2 \%$, on average. Results for TA07 are summarized in Table 4. The results indicate that the pretest shell model (i.e., untuned model) under predicts the eigenvalues by between $2.0 \%$ and $6.3 \%$. A typical global eigenmode, mode 1, is shown in Fig 24a, and a typical local eigenmode, mode 10, is shown in Fig. 24b.

Table 4. Eigen value results for untuned and tuned TA07 shell model

\begin{tabular}{|c|c|c|c|c|c|}
\hline Mode \# & Creo Solid E.V. & $\begin{array}{c}\text { Abaqus E.V., } \\
\text { untuned }\end{array}$ & $\begin{array}{c}\text { Abaqus \% } \\
\text { diff. }\end{array}$ & $\begin{array}{c}\text { Abaqus E.V., } \\
\text { tuned }\end{array}$ & $\begin{array}{c}\text { Abaqus tuned } \\
\text { \% diff. }\end{array}$ \\
\hline 1 & 1.000 & 0.957 & -4.3 & 0.988 & -1.2 \\
\hline 2 & 1.680 & 1.622 & -3.4 & 1.664 & -1.0 \\
\hline 3 & 2.034 & 1.944 & -4.4 & 2.031 & -0.2 \\
\hline 4 & 2.310 & 2.227 & -3.6 & 2.292 & -0.8 \\
\hline 5 & 2.932 & 2.873 & -2.0 & 2.892 & -1.4 \\
\hline 6 & 3.225 & 3.124 & -3.2 & 3.173 & -1.6 \\
\hline 7 & 3.278 & 3.130 & -4.5 & 3.211 & -2.0 \\
\hline 8 & 3.287 & 3.154 & -4.0 & 3.218 & -2.1 \\
\hline 9 & 3.521 & 3.339 & -5.2 & 3.434 & -2.5 \\
\hline 10 & 3.781 & 3.543 & -6.3 & 3.655 & -3.3 \\
\hline
\end{tabular}




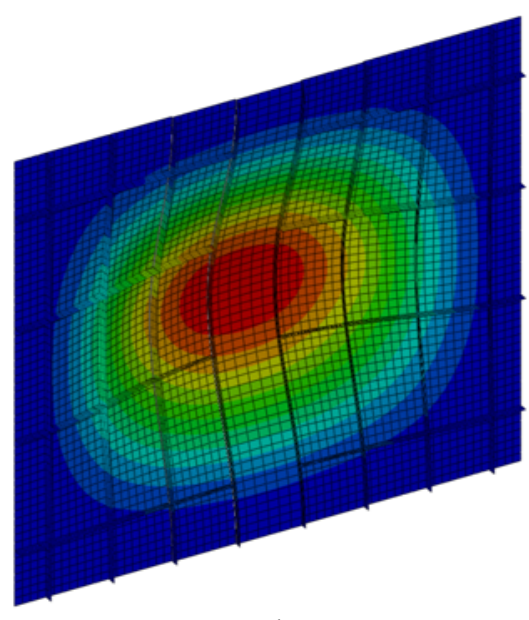

Mode 1

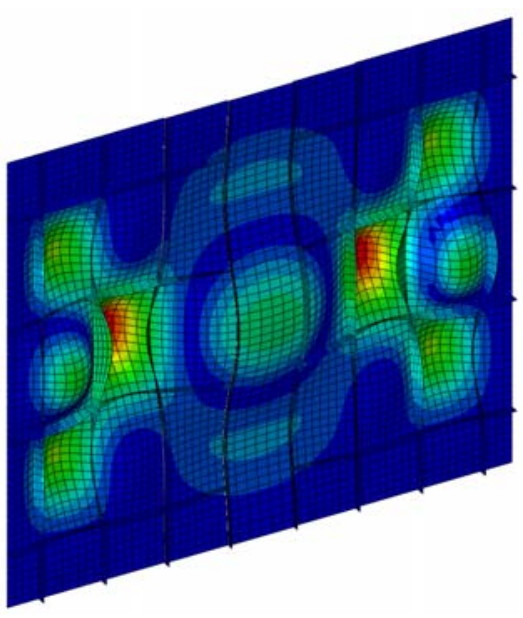

Mode 10

Figure 24. Typical eigenmode shapes used to adjust the shell model thickness properties in the fillet locations.

The modified stiffener thicknesses derived from the tuning process were added to the TA07 cylinder model and resulted in a $4.2 \%$ increase in the buckling load, and an increase in the effective axial stiffness of less than $1 \%$. Similar results were found for other orthogrid stiffened cylinder test articles. Additional fillet detail also resulted in noticeable increases in the buckling load and effective axial stiffness of isogrid-stiffened cylinders tested by SBKF. In particular, the buckling load and stiffness of isogrid test article ITA02 increased by $10 \%$ and $3.1 \%$, respectively.

\section{End imperfection}

The geometry of the top and bottom attachment ring interface surfaces were measured after the rings were installed onto the TA to insure that they met the assembly tolerances discussed in Section III. The measured geometry of the top and bottom attachment rings used in the TA07 test are shown in Figs. 25a and 25b, and correspond to the deviation from a best-fit plane. The measurements indicate a periodic variation in the surface geometry around the circumference of the rings of less than \pm 0.015 inch, and were within the specified machining tolerances. Previous studies by SBKF and others have shown that small variations in the loading surface geometry (a.k.a. loading imperfections), such as these, lead to nonuniform loading in the test article and can have a significant influence on the buckling response. ${ }^{7}$ Thus, the effects of these measured loading surface imperfections presented were modeled and assessed. Data was extracted from these measurements for use in the analysis and is plotted in Fig. 25c. The modeling of the end imperfection was achieved using a three-step process. First, the measured loading surface imperfection data was used to perturb the axial location of the nodes at both ends of the cylinder replicating the nonuniform loading surface. Next, the loading surface imperfection data was used to define a set of applied displacements that simulate the attachment of the nonuniform attachment ring surfaces to the adjacent load introduction structure, bringing the TA end nodes into an idealized flat and parallel condition. This step resulted in some amount of preloading to the TA. Finally, loading was applied to the TA to simulate the test loading conditions. 


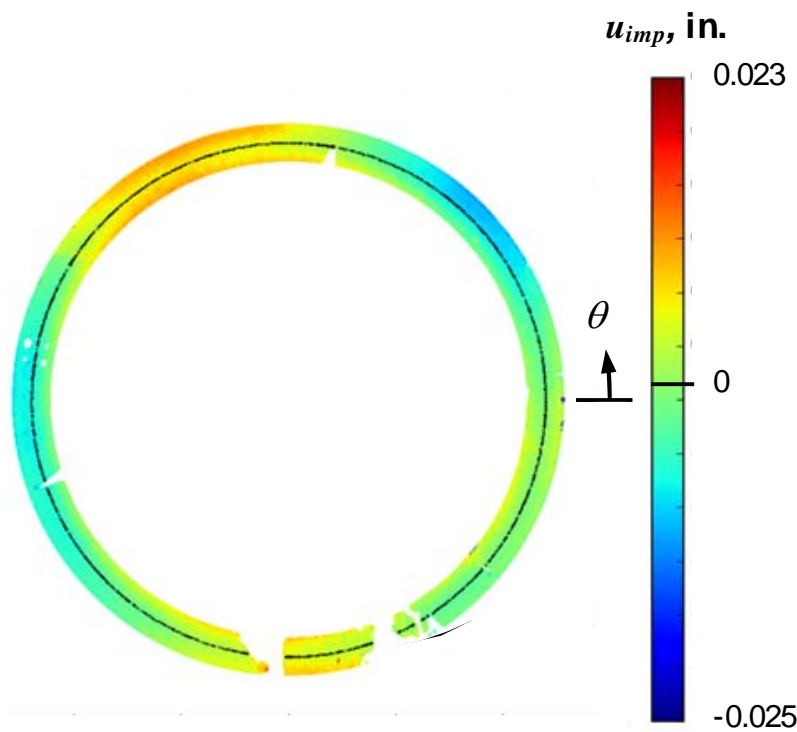

a) Top attachment ring

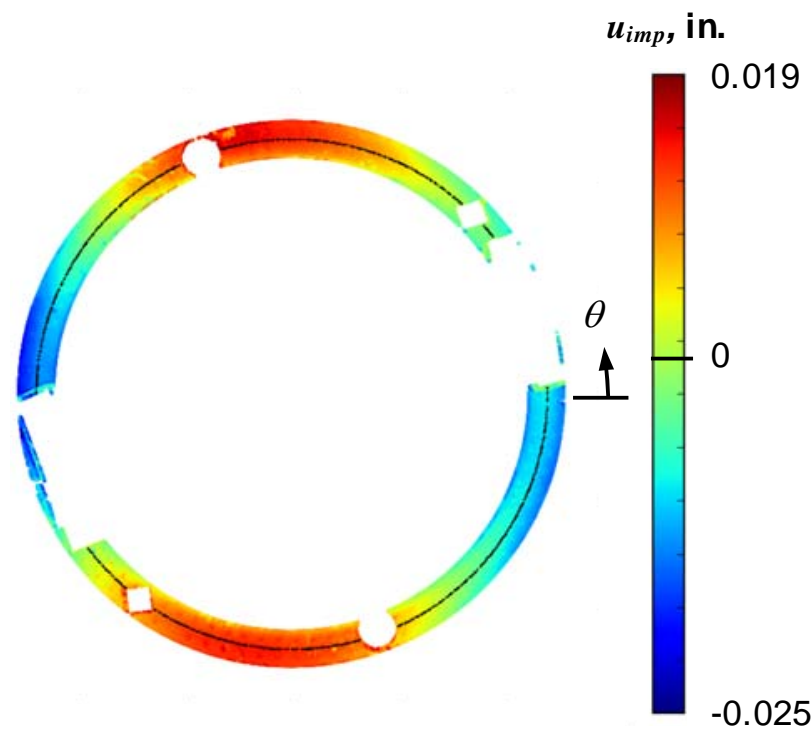

b) Bottom attachment ring

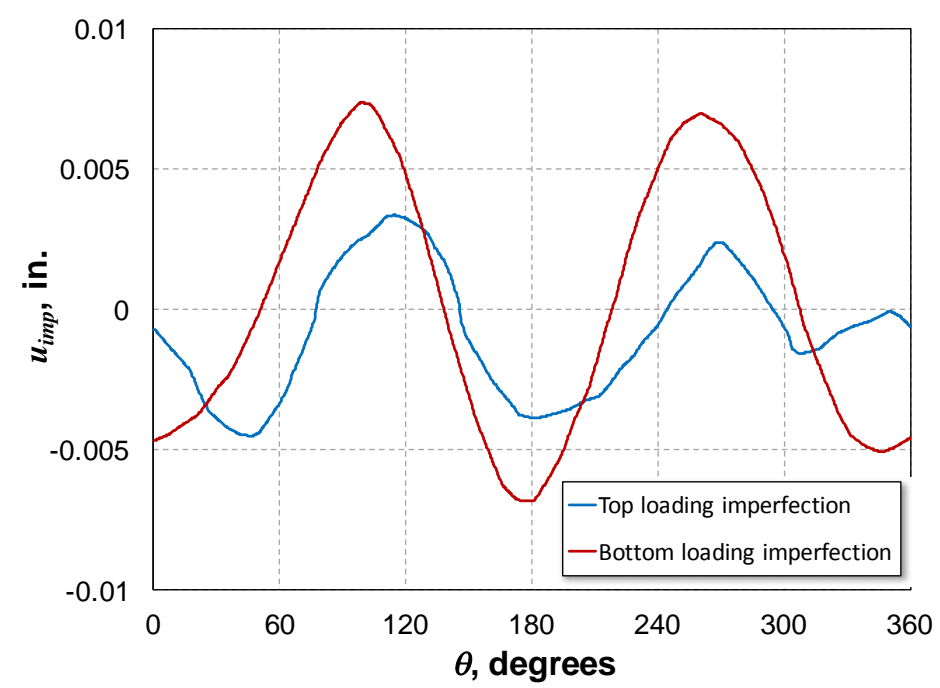

c) Extracted top and bottom attachment ring flange imperfection data

Figure. 25 Measured attachment ring interface surface imperfections.

The analysis of TA07, with the measured loading surface imperfection, resulted in a $1.8 \%$ reduction in the buckling load as compared to the pretest prediction. More importantly, the loading imperfection moved the predicted buckling initiate location from weld land $A / B$ to weld land $B / C$, the same location that was observed in the test.

\section{Summary of the sensitivity study}

The results from the sensitivity study indicate that all the modeling assumptions had an effect on the buckling response to varying degrees. A summary of the load-end-shortening curves is shown in Fig. 26 illustrating the variation in buckling load and effective axial stiffness for the modifications considered. The skin and stiffener thickness, geometric imperfection amplitude, and fillet representation had the most noticeable effects on increasing the buckling load. Similarly, a summary of load versus radial displacement response curves are shown for panel C and weld B/C in Fig. 27. The results indicated that the overall character of the displacement response at the center of panel C was somewhat sensitive to the modifications considered, as shown in Fig. 27a. However, the end imperfection (End Imp Scaled) and the attachment ring modeling (Ring Boundary) had a significant influence on the displacement response at weld land $\mathrm{B} / \mathrm{C}$. 


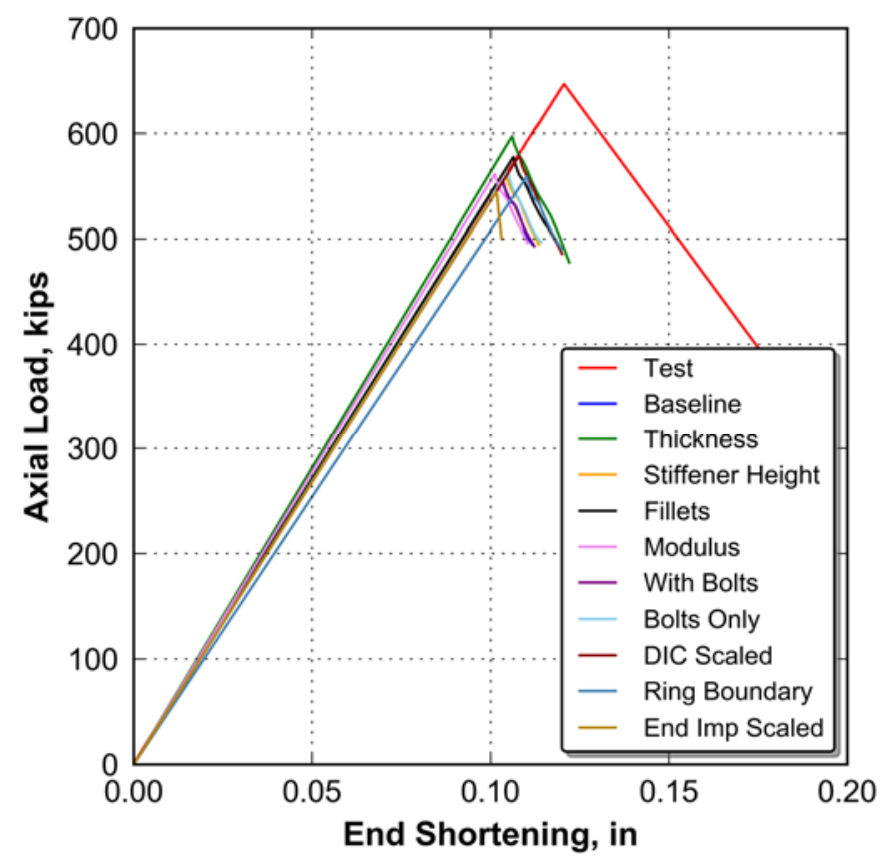

Figure 26. Summary of load versus end-shortening response curves from TA07 sensitivity study.

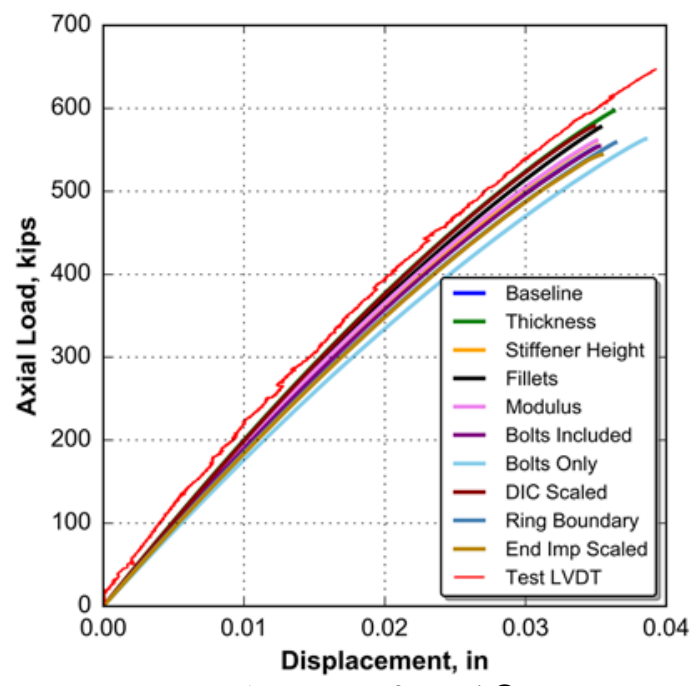

a) Center of panel C

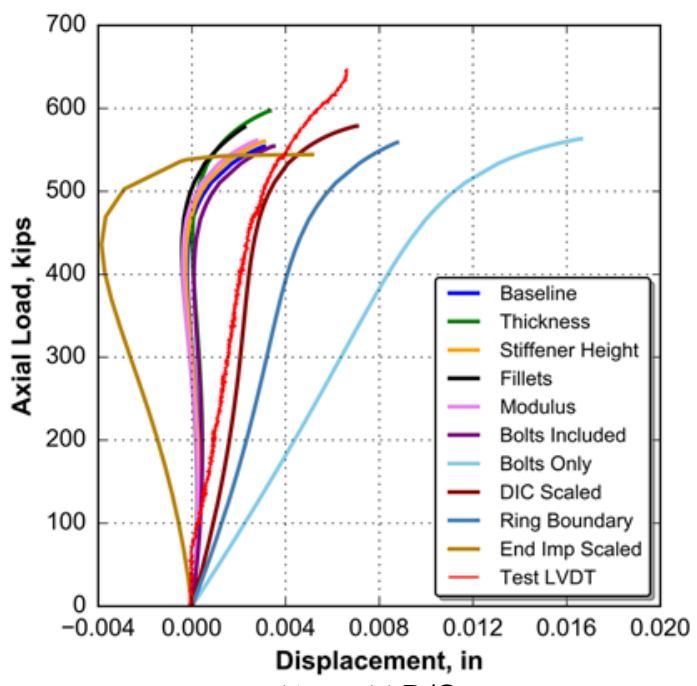

b) Weld B/C

Figure 27. Summary of load versus radial displacement response curves from TA07 sensitivity study.

\section{Refined Model and Test Results}

A final refined analysis model for TA07 was developed and included all the modifications presented in the previous section, as summarized in Table 3. The results of the refined model are presented here and are compared to the test results and the pretest predictions.

The measured load end-shortening response is compared to the results from the pretest and refined models in Fig. 28. The refined model predicted a buckling load within $1 \%$ of the measured buckling load. The predicted radial displacements incipient to buckling are shown in Fig. 29 and indicate good agreement with the measured DIC results presented in Fig. 15b. In particular, the initiation of buckling was predicted to occur near the bottom of weld land B/C, which was observed in the test. Finally, the measure load versus radial displacement response curves at the center of panel $C$ and the center weld land $B / C$ are shown in Fig. 30. These results indicate a significant improvement in the predicted response achieved with the refined model. 


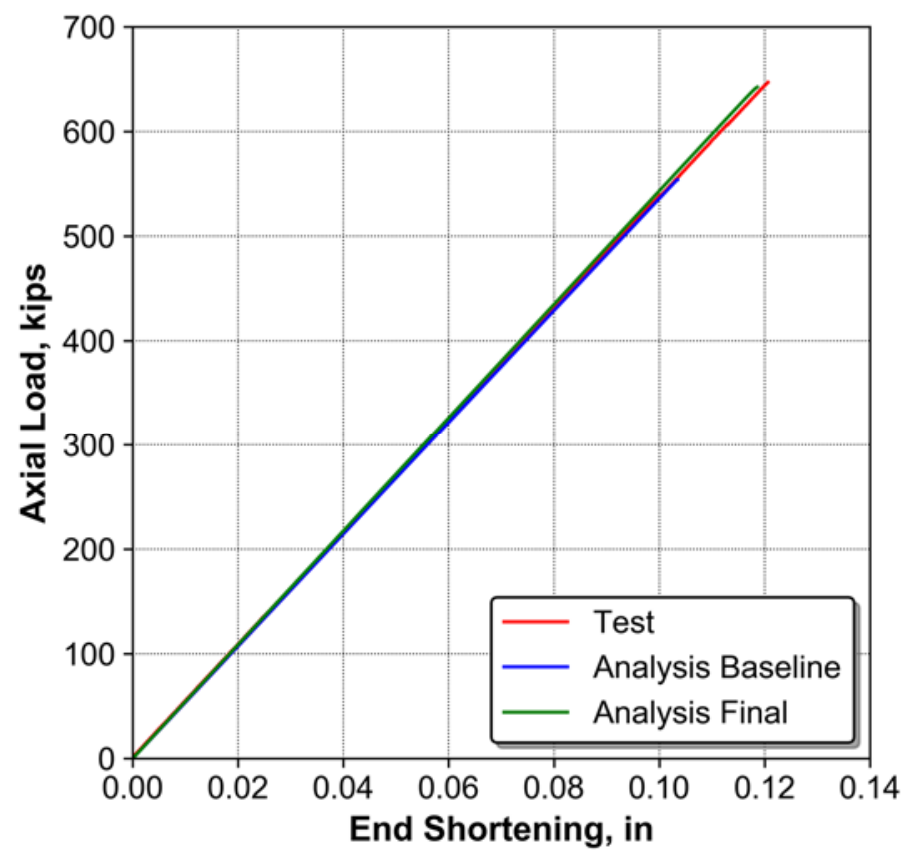

Figure 28. Predicted and measured load versus end-shortening response curves for TA07, including results from baseline and refined models.

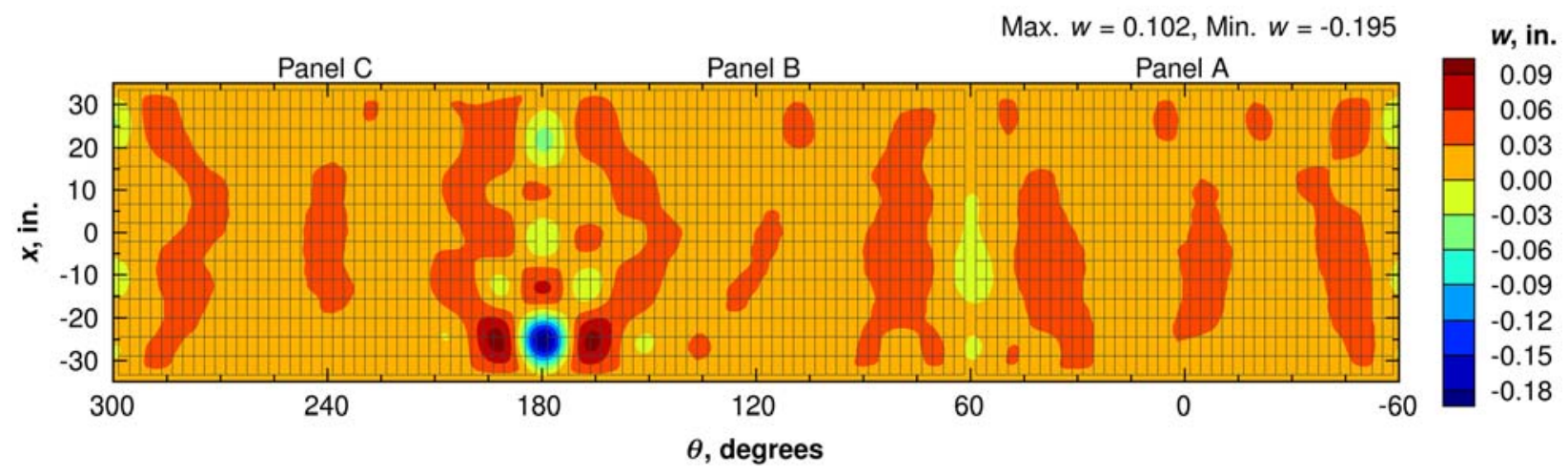

Figure 29. Predicted incipient buckling radial displacements for TA07 subjected to axial compression. 

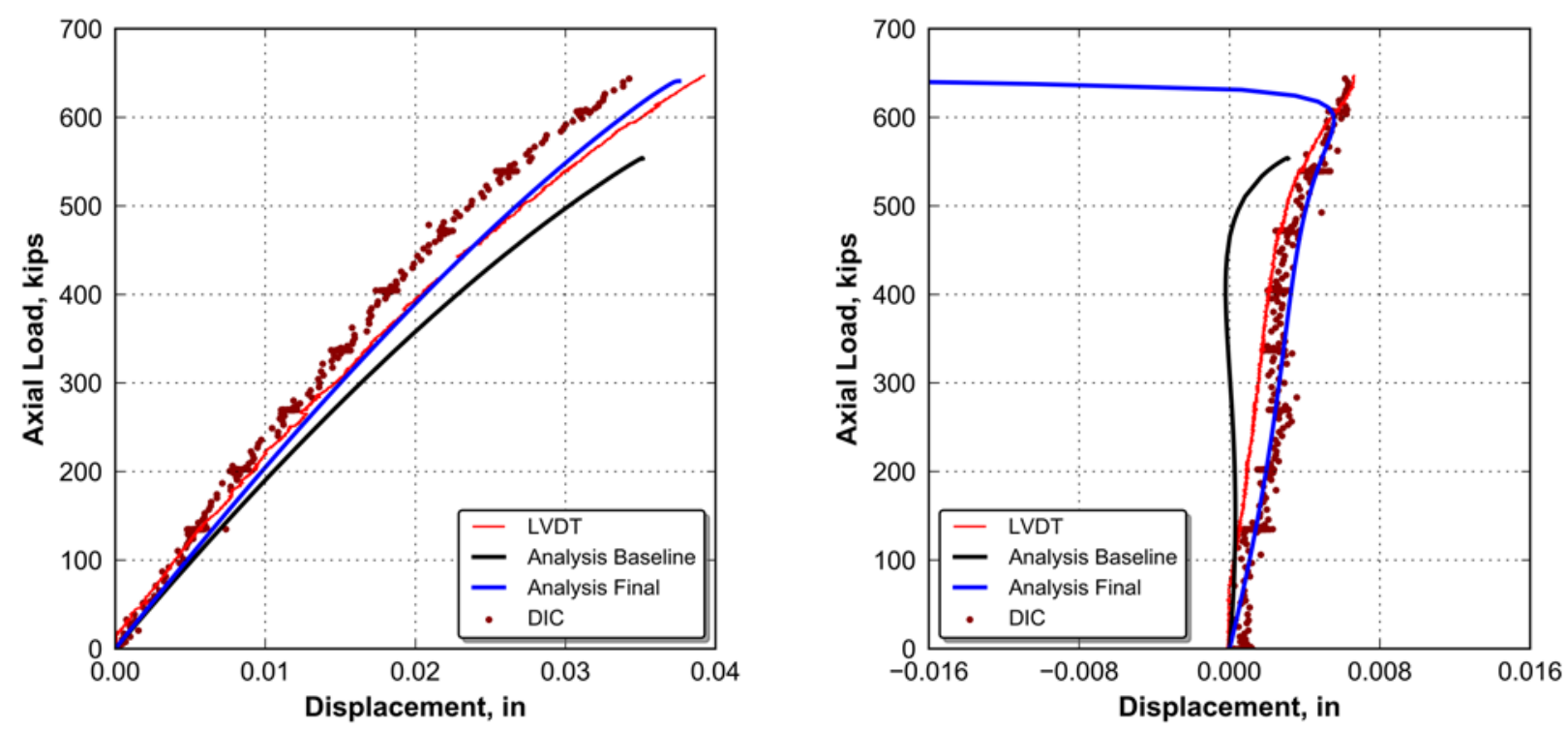

Figure 30. Predicted and measured load versus radial displacement curves for TA07, including results from baseline and refined models.

\section{Concluding Remarks}

Eight subscale 8-ft-diameter integrally-stiffened metallic cylinders were fabricated and tested by the SBKF project. The data obtained from these tests is being used to develop and validate high-fidelity buckling simulations and new analysis-based knockdown factors for buckling-critical launch vehicle cylinders. Selected test and finite element analysis results from the orthogrid-stiffened cylinder test article TA07 were presented and used to illustrate the typical response characteristics of the stiffened metallic cylinders considered in the SBKF test program. Overall, good qualitative agreement was found between the test and analysis results, although several discrepancies in the results were identified. In particular, the predicted buckling load of TA07 was $14.4 \%$ less than the measured buckling load. In addition, the load versus radial displacement response curves of the axial weld lands did not correlate well with LVDT-based and DIC-based measurements. The discrepancies were thoroughly investigated using a detailed sensitivity study and were attributed to; variations in the as-built skin and stiffener geometry, dissimilarities in the measured geometric imperfections, loading discrepancies, and modeling assumptions associated with the boundary conditions. An updated finite element model of TA07 was developed to provide a more accurate representation of the as-tested configuration. This new model resulted in a significant improvement in the predicted buckling response.

\section{Acknowledgments}

This work was conducted as part of the NASA Engineering and Safety Center (NESC) Shell Buckling Knockdown Factor Project, NESC Assessment \#:07-010-E.

\section{References}

${ }^{1}$ Peterson, J. P., Seide, P., Weingarten, V. I., "Buckling of Thin-Walled Circular Cylinders," NASA Space Vehicle Design Criteria, NASA SP-8007, September 1965 (Revised 1968).

${ }^{2}$ Peterson, J. P., Seide, P., Weingarten, V. I., "Buckling of Thin-Walled Truncated Cones," NASA Space Vehicle Design Criteria, NASA SP-8019, September 1968.

${ }^{3}$ Peterson, J. P., Seide, P., Weingarten, V. I., "Buckling of Thin-Walled Doubly Curved Shells," NASA Space Vehicle Design Criteria, NASA SP-8032, August 1969.

${ }^{4}$ Meyer, R. R., Harwood, O. P., and Orlando, J. L., "Isogrid Design Handbook," NASA CR-124075, February 1973.

${ }^{5}$ Nemeth, M. P., "A Treatise on Equivalent-Plate Stiffnesses for Stiffened Laminated-Composite Plates and Plate-Like Lattices," NASA/TP-2011-216882, January 2011. 
${ }^{6}$ Lovejoy, A. E., Hilburger, M. W., and Gardner, N. W., "Test and Analysis of Full-Scale 27.5-Foot-Diameter Stiffened Metallic Launch Vehicle Cylinders," Proceedings of the 59 th AIAA/ASME/ASCE/AHS/ASC Structures, Structural Dynamics and Materials Conference, Kissimmee, FL, 2018 (submitted for publication).

${ }^{7}$ Abaqus/Standard, Software Package, Ver. 6.14-1, SIMULIA, Providence, RI, 2014.

8"Design Allowables Handbook for Aluminum-Lithium 2195 Plates, Extrusions, Forgings, \& Welds", MSFC

HDBK-3513 (Baseline).

${ }^{9}$ Hilburger, M. W., and Starnes, J. H., Jr., "Parametric Study on the Response of Compression-Loaded Composite Shells with Geometric and Material Imperfections," NASA/TM-2004-212676, September 2004S. 